I MF STAFF DISCUSSION NOTE

\title{
Dealing with High Debt in an Era Of Low Growth
}

S. Ali Abbas, Bernardin Akitoby, Jochen Andritzky Helge Berger, Takuji Komatsuzaki, Justin Tyson 
INTERNATIONAL MONETARY FUND

European and Fiscal Affairs Departments

\author{
Dealing with High Debt in an Era of Low Growth \\ Prepared by S. Ali Abbas, Bernardin Akitoby, Jochen Andritzky, \\ Helge Berger, Takuji Komatsuzaki, Justin Tyson ${ }^{1}$
}

Authorized for distribution by Carlo Cottarelli and Reza Moghadam

September 2013

DISCLAIMER: This Staff Discussion Note represents the views of the authors and does not necessarily represent IMF views or IMF policy. The views expressed herein should be attributed to the authors and not to the IMF, its Executive Board, or its management. Staff Discussion Notes are published to elicit comments and to further debate.

JEL Classification Numbers: E62, H60

Keywords:

General Government Debt, Public Debt Sustainability, Fiscal Consolidation

Author's E-mail Addresses: $\quad$ sabbas@imf.org, bakitoby@imf.org, jandritzky@imf.org, hberger@imf.org, tkomatsuzaki@imf.org, jtyson@imf.org

\footnotetext{
${ }^{1}$ We would like to thank Ariel Binder, Vizhdan Boranova, and Thomas Dowling for excellent research assistance. Aasim M. Husain and Gerd Schwartz provided helpful comments and guidance.
} 


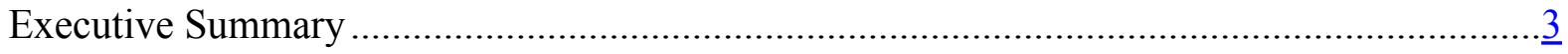

I. Public Debt in Advanced Economies: The Scale of the Problem .........................................

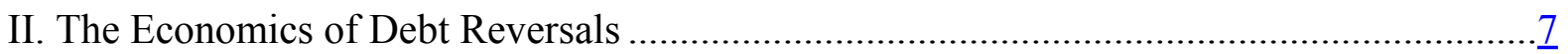

A. First Cut: A Look at What Drives the Debt Ratio....................................................

B. The Mechanics: Growth, Fiscal Policy, and Interest Rates.....................................12

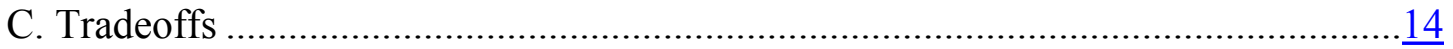

III. Large Debt Reversals in the Past ................................................................................

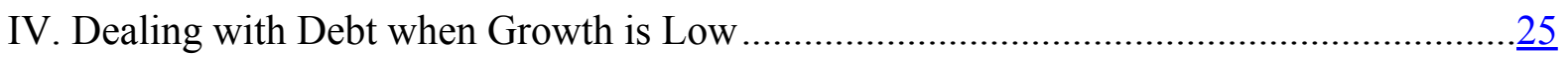

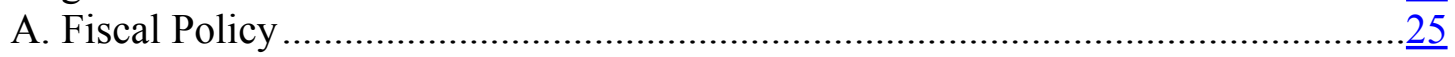

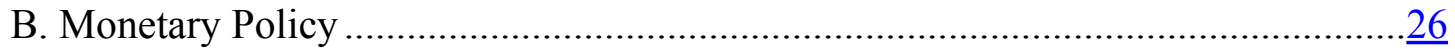



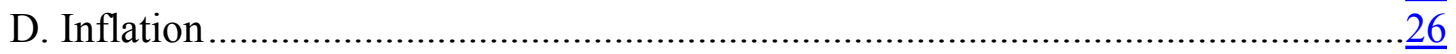

E. Structural Reform to Lift Longer-Term Growth .................................................27

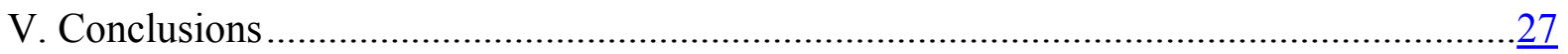

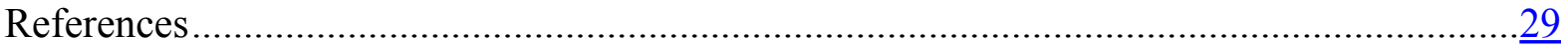

Table

1. Main Macroeconomic Indicators for Selected Advanced Economies ...................................

Figures

1. Developments in Gross Debt and Structural Balance in Advanced Economies......................

2. Density of Debt Changes Conditional on Macroeconomic Variables ................................... 9

3. Contribution to Annual Debt Ratio Reductions...........................................................

4. Debt Ratio Changes Conditional on Growth and Interest Rates..........................................11

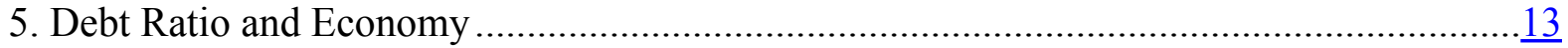

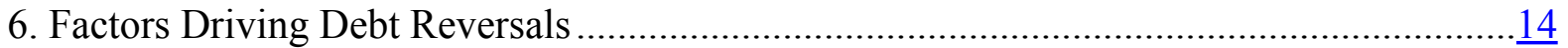

7. Growth and Primary Balance Paths for Achieving a Given Debt Reduction ....................... $\frac{15}{15}$

8. Debt Reversals with Credibility Effects .....................................................................

9. Components of Major Debt Reductions in Advanced Economies Since 1980 …………..... 18

10. Real GDP Growth, Structural Primary Balance, and Size of Initial Debt ..........................18

11. Size of Debt Reduction vs. Initial Levels of Key Variables ............................................

12. Evolution of Key Variables tThrough Deficit Reduction Episode ...................................22

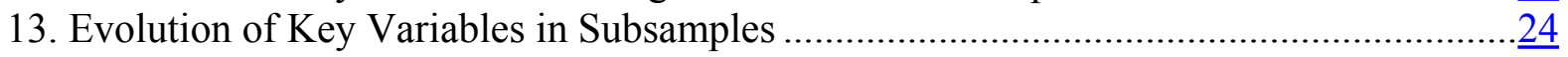

Annexes



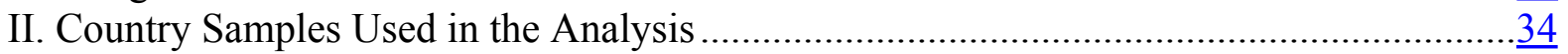

III. Major Debt Reduction Episodes in Advanced Economies Since 1980 ..............................

IV. Relationship Between Primary Balance, Debt-to-GDP Ratio, and Growth ........................ $\frac{35}{37}$

V. Illustrative Framework for Debt Dynamics Equation....................................................... 


\section{EXECUTIVE SUMMARY}

Dealing with high public debt is never easy, but for many advanced economies the current environment poses new challenges. ${ }^{2}$ Sovereign debt is approaching historical highs, largely reflecting the work of automatic stabilizers, counter-cyclical fiscal policy, and financial sector bail-outs. However, a weak medium-term growth outlook complicates the task of putting debt back on a clearly declining path. This shifts the burden of adjustment on fiscal policy at a time when fiscal accounts are already under pressure from underlying structural changes, such as continued population aging and rising health-care spending.

In the past, output growth and fiscal adjustment were the main drivers behind debt reversals. An analysis of 26 episodes of large debt reversals in advanced economies since the 1980s and other empirical evidence suggest that periods of decreasing debt were often associated with higher growth rates and strong primary balances. Inflation, interest rates, and stock-flow adjustments also affected debt dynamics, although they played relatively minor roles. Historically, debt reductions have tended to be smaller and less frequent in more challenging macroeconomic environments of moderate growth and higher interest rates; when debt reductions have succeeded under such conditions, it was mostly due to a strong fiscal effort.

Front-loaded consolidations, in particular, have tended to increase public debt in the short run, even as risk premiums fell. Empirically, fiscal effort has been more likely to reduce public debt when growth has been stronger. Illustrative calculations show how the debt-to-GDP ratio increases in the short run when fiscal consolidations come at the cost of lower economic activity. Front-loaded consolidation can lead to greater output loss than a gradual effort does, even though it can also reduce the overall magnitude of the adjustment needed. In addition, while credibility effects can ease the pain of fiscal adjustment through lower risk premiums, this is unlikely to fully offset the short-run adverse impact on economic activity.

Some of the most successful historical public debt reversals also started under adverse circumstances - such as high debt, high interest rates, and low initial rates of growth - and provide encouraging examples for the task ahead: ${ }^{3}$ The typical growth-interest rate differential was close to zero. Ultimately, supportive external demand and monetary policy helped economic growth and offset the contractionary impact of initial large fiscal adjustments. Typically, reductions in debt-to-GDP ratios have coincided with pick-ups in growth. Fiscal efforts continued as growth improved, leading to high primary surpluses.

The current and expected future growth environments, though, might pose a particular challenge for successful debt reduction. Based on current WEO projections, average output growth in advanced economies during the 2013-2018 period could be almost 1 1/2 percentage points below the rates enjoyed by these same economies during 1980-2007. Moreover, other options for reducing debt are unlikely to provide much support: privatizations and asset sales

\footnotetext{
${ }^{2}$ The terms public debt, sovereign debt and debt are used interchangeably in this paper, but all refer to the same concept: gross general government debt recorded at face value, as a share of GDP. For countries where data on general government debt were not available, central government debt data were used instead.

${ }^{3}$ This is also broadly the conclusion of other papers on this topic. See, for example, IMF (2012, Chapter 3).
} 
remain challenging, particularly given the weak growth outlook and the fact that many assets are held by local authorities. Other options, such as reducing debt through higher inflation, may be unavailable and, in any case, would come with their own significant risks.

Hence, debt reductions will require both a sustained commitment to fiscal consolidation and careful design. With the burden of adjustment falling on fiscal consolidation, the cost to growth could be sizable in the short term and may initially increase the debt ratio because of fiscal multiplier effects. This highlights the importance of getting the pace of fiscal consolidation right and acting, where possible, to mitigate the short-run growth impact. A gradual pace of fiscal adjustment will be credible only if embedded in a medium-term fiscal consolidation strategy buttressed by strong budget institutions. Other growth-enhancing measures, such as structural reforms, will be important to improve growth potential in the medium term and to help reduce the debt ratio durably. Where fiscal accounts are weaker and sovereign interest rates are higher, the pace of adjustment will have to be more ambitious, bearing in mind the limits to social and political cohesion beyond which fiscal adjustment can be counterproductive.

The paper is organized in five main sections. Section I discusses the scale of the problem, which is unprecedented, at least in peacetime. Section II focuses on the economics of debt reversals, using several methodologies to decompose changes in debt-to-GDP ratios and explore trade-offs. Section III analyzes large debt reversals in the past. Section IV discusses policy alternatives to support fiscal adjustment processes, and Section $\mathrm{V}$ concludes. 


\section{Public Debt in Advanced Economies: The Scale of the Problem}

Sovereign debt in many advanced economies is approaching historical highs. ${ }^{4}$ The median debtto-GDP ratio in advanced economies rose from around 45 percent at the start of the crisis to about 74 percent by the end of 2012 - a level not seen since the years just after World War II (Figure 1). ${ }^{5}$ The current debt-to-GDP ratio is at about 90 percent or higher for many G7 economies and a number of euro area economies (Table 1). Debt ratios in these countries are forecast to peak in 2013-14 at levels some 40 percent of GDP above their pre-crisis levels.

The debt surge reflects the direct effect of the recession as well as other factors. The collapse in revenues caused by the Great Recession has been a key driver of the debt build-ups. According to IMF (2013), more than half of the debt build-up in G-20 Advanced Economies is explained by the loss of potential output and the related fall in revenues, while the fiscal stimulus accounted for about 17 percent. That said, given the feedback between fiscal policy and growth, the reduction in output levels and the resulting increase in the debt-ratio would likely have been worse without the fiscal stimulus (see Section II). Overall, structural balances in advanced economies worsened by about 4 percent of GDP on average before recovering (Figure 1).

\section{Figure 1. Developments in Gross Debt and Structural Balance in Advanced Economies}

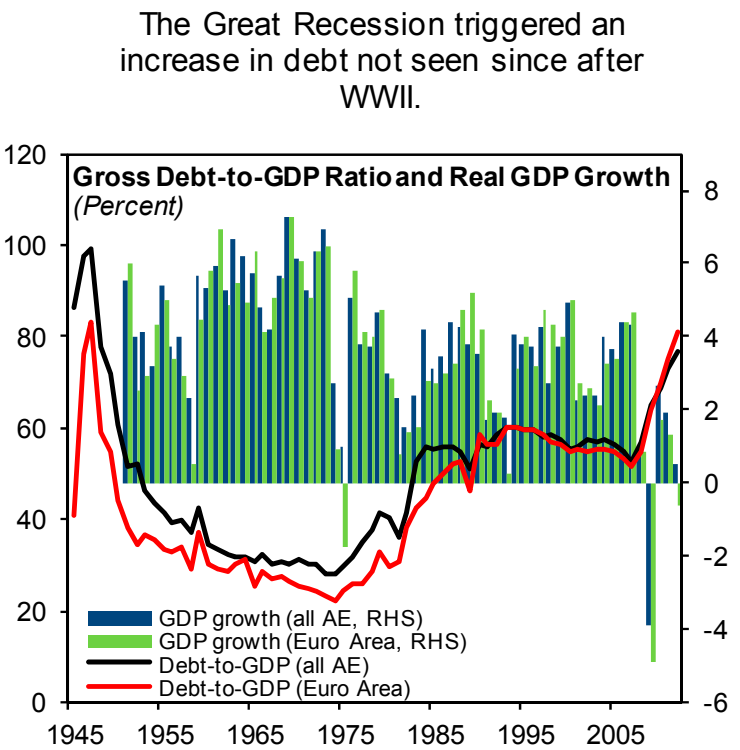

After worsening in context of the crisis, structural balances started to recover.

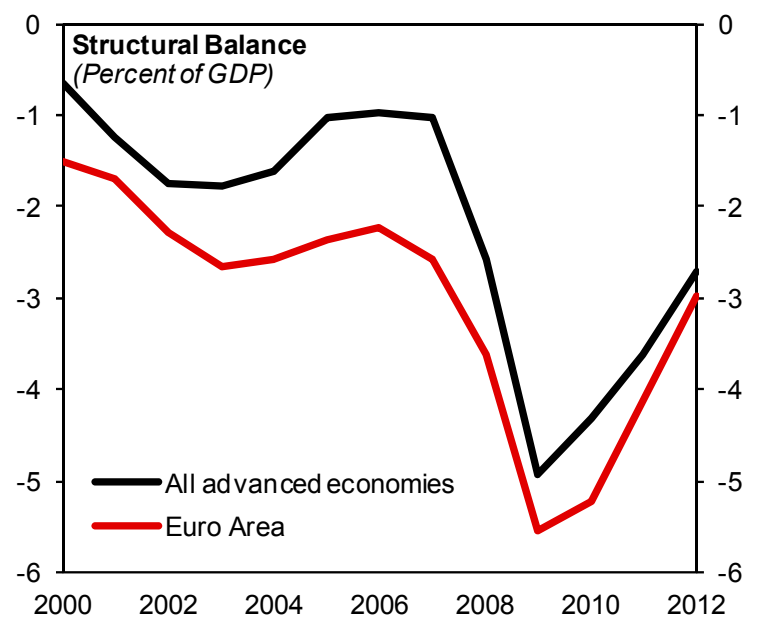

Sources: Historical Public Debt Database, IMF Fiscal Monitor, IMF World Economic Outlook, and IMF staff calculations.

\footnotetext{
${ }^{4}$ The sample includes 30 advanced economies listed in the Fiscal Monitor (see Annex II) and the three euro-area economies not in the advanced economies sample (Cyprus, Luxembourg, and Malta).

${ }^{5}$ GDP weighted averages are higher, increasing from about 60 percent at the start of the crisis to about 100 percent of GDP (see IMF, 2013).
} 
High and increasing levels of public debt can lead to higher interest rates and slower growth. While the idea of precise "debt thresholds" remains under discussion, many studies find that high debt levels have a negative effect on growth (IMF, 2013). High debt also makes public finances more vulnerable to future shocks, both by constraining the ability of governments to engage in countercyclical policies and by increasing the primary surplus needed to stabilize the debt ratio following an adverse shock to growth or interest rates. Indeed, when debt is high, there is a risk of falling into a bad equilibrium caused by self-fulfilling expectations.

Looking forward, the looming surge of age-related spending will complicate the task for countries that have to bring down high debt. Not only are there no obvious areas for expenditure adjustment — such as the politically easy-to-implement military spending cuts after World War II - but age-related health care spending in advanced economies is estimated to increase by more than 3 percentage points of GDP over the next 20 years. At the same time, pension spending is projected to rise by over 1 percentage point of GDP during the same period (IMF, 2013).

Even more important is the diminished outlook for growth. The household, corporate, and financial-sector deleveraging that followed the financial crisis dampens the growth outlook in the medium-term. Based on current WEO projections, average output growth in advanced economies will be about 2 percent during the 2013-18 period, significantly below the 3.3 percent growth that the same economies recorded during 1980-2007. Long-term growth, too, will likely remain below the 1980-2007 rates, given the projected decline in the labor force in advanced economies (Cottarelli, 2013). Lower growth not only means higher structural deficits as tax revenue weakens and spending plans struggle to adjust to the low-growth environment; it also affects the debt ratio through the denominator (see Section II).

The combination of low growth and high interest rates makes debt reversal particularly challenging for some high-debt countries. When interest rates are high, financing debt becomes more expensive, complicating efforts to reduce debt. The financial crisis has led to sharply higher interest rates for countries with low growth rates facing market pressures (e.g., in the euro area periphery). In other countries perceived as "safe havens," interest rates have fallen and growth rates have been less weak (Table 1). Given the uncertainty surrounding both, it is not easy to predict the future path of the interest rate-growth differential, which is what influences debt dynamics. 
Table 1. Main Macroeconomic Indicators for Selected Advanced Economies

\begin{tabular}{|c|c|c|c|c|c|c|}
\hline & \multicolumn{2}{|r|}{2012} & \multicolumn{4}{|c|}{ 2013-18 Average Forecast } \\
\hline & Debt * & $\begin{array}{l}\text { Real Marginal } \\
\text { Interest Rate }\end{array}$ & $\begin{array}{l}\text { Inflation } \\
\text { Rate }\end{array}$ & $\begin{array}{l}\text { Real Average } \\
\text { Interest Rate }\end{array}$ & $\begin{array}{c}\text { Real Growth } \\
\text { Rate }\end{array}$ & $r-g$ \\
\hline \multicolumn{7}{|l|}{ Selected Euro } \\
\hline France & 90.3 & 0.6 & 1.6 & 1.2 & 1.0 & 0.2 \\
\hline Germany & 82.0 & -0.5 & 1.8 & 1.3 & 1.1 & 0.2 \\
\hline Ireland & 117.6 & 4.1 & 1.6 & 2.5 & 2.1 & 0.4 \\
\hline Italy & 127.0 & 2.2 & 1.8 & 3.0 & 0.1 & 2.9 \\
\hline Portugal & 123.0 & 7.8 & 1.5 & 2.6 & 0.1 & 2.5 \\
\hline Spain & 84.1 & 3.4 & 1.7 & 3.0 & 0.3 & 2.7 \\
\hline \multicolumn{7}{|l|}{ Non-Euro G7 } \\
\hline Canada & 85.6 & 0.4 & 1.8 & 2.3 & 2.2 & 0.2 \\
\hline Japan & 237.9 & 0.9 & 1.1 & 0.7 & 1.4 & -0.7 \\
\hline United Kingdom & 90.3 & -0.2 & 2.4 & 1.5 & 1.4 & 0.2 \\
\hline United States & 106.5 & -0.3 & 1.9 & 0.9 & 2.9 & -2.0 \\
\hline
\end{tabular}

Sources: IMF Fiscal Monitor, IMF World Economic Outlook, and IMF staff calculations.

* Percent of GDP.

\section{THE ECONOMICS OF DEBT REVERSALS}

\section{A. First Cut: A Look at What Drives the Debt Ratio}

Identifying the factors moving the debt-ratio is not always straightforward. For example, while Figure 1 implies some association between low or negative growth rates, weak primary balances, and debt ratios, the underlying correlations seem to vary across countries and time. This suggests the need for a more systematic investigation of the underlying drivers of the debt ratio.

A first look suggests that the primary fiscal balance plays an important role. Based on a sample of four-year changes in the debt-ratio of 30 advanced economies between 1980 and 2011, debt reduction spells are more frequent during periods with higher primary balances (that is, the fiscal balance excluding interest payments). ${ }^{6}$ Similarly, debt increases are more frequent when primary balances are below average. Figure 2 (top left panel) shows four-year changes in the debt-to-GDP ratio conditioned on whether the cumulative primary balance over the period is above (high) or below (low) the country-specific median. The picture is substantially the same when conditioning changes in the debt-to-GDP ratio on the structural primary balance, suggesting that discretionary policy action contributed to these changes (Annex IV, top panels). ${ }^{7}$

\footnotetext{
${ }^{6}$ The sample includes the 30 advanced economies listed in the Fiscal Monitor (IMF, 2013), excluding Israel (due to hyperinflation in the 1980s), Norway, and Singapore (due to their particular net asset positions).

${ }^{7}$ Structural primary balances were calculated using the standard assumption of output gap elasticities of 1 and 0 for revenues and expenditure, respectively. The output gap was obtained as a percentage deviation of real GDP from its HP-filtered trend (i.e., potential output). A smoothing parameter of 100 was employed and the usual "end-
} 
Growth appears to be the other key factor. The historical record confirms that a decline in the debt ratio is more likely when real GDP growth is high. Figure 2 (top right panel) shows 4-year changes in the debt-to-GDP ratio conditioned on whether growth over the four years is above (high) or below (low) the country-specific median. Other factors, such as inflation, interest rates, and stock-flow adjustments (SFAs), ${ }^{8}$ also affect debt dynamics. However, their impact on the distribution of changes in debt-ratios is less clear cut than for fiscal effort and output growth (Figure 2, bottom panels).

A decomposition of debt-reduction spells, using standard debt-dynamics calculations, seems to confirm these impressions. ${ }^{9}$ For all debt reduction episodes the combined growth effect (i.e., the sum of the impact of real GDP growth and automatic stabilizers) reduced the debt ratio by 2 percent of GDP annually. By contrast, the structural primary balance contributed to a debt reduction of 3.2 percent of GDP per year. The interest rate bill is another relevant factor: interest expenditure added more than 3 percentage points of GDP annually to the debt stock, on average (Figure 3).

SFAs and the net impact of inflation play a much smaller role. SFAs were only a relatively small factor during debt reduction spells, increasing the debt ratio by about 1 percentage point, on average. The inflation component in Figure 3 depicts its direct effect through higher nominal GDP, reducing the debt ratio via the denominator. However, higher inflation also increases interest expenditure through the Fisher effect, which reduces the net impact of inflation in our sample. ${ }^{10}$

point problem" mitigated through use of long time series/projections. While this approach ensures a good degree of comparability across countries, it does not strip out asset-price-linked revenue booms or busts. Use of datasets on action-based consolidations (such as the one documented by Devries and others, 2011) can help avoid this pitfall, but such datasets offer narrower country coverage and may not be as strictly comparable across countries as they depend on the quality of available documentation.

${ }^{8}$ SFAs reflect the difference between the annual change in gross debt and the budget deficit. They can arise for different reasons, including valuation changes and other transactions that affect debt but not the deficit (such as the privatization or realization of contingent liabilities) (Baum, Poplawski-Ribeiro, and Weber, 2012).

${ }^{9}$ Debt-reduction spells are defined as at least four years of declining debt ratios, allowing for one exception year. For example, a period of four years that combines three years of debt reduction with one year when the debt ratio increases up to two percentage points will be included in the sample.

${ }^{10}$ Note that other components of the decomposition, such as the primary balance, can also be indirectly affected by inflation, through the revenue collected by the government - the so-called Tanzi effect (Escolano, 2010). 
Figure 2. Density of Debt Changes Conditional on Macroeconomic Variables

Debt declines are associated with higher primary balances...

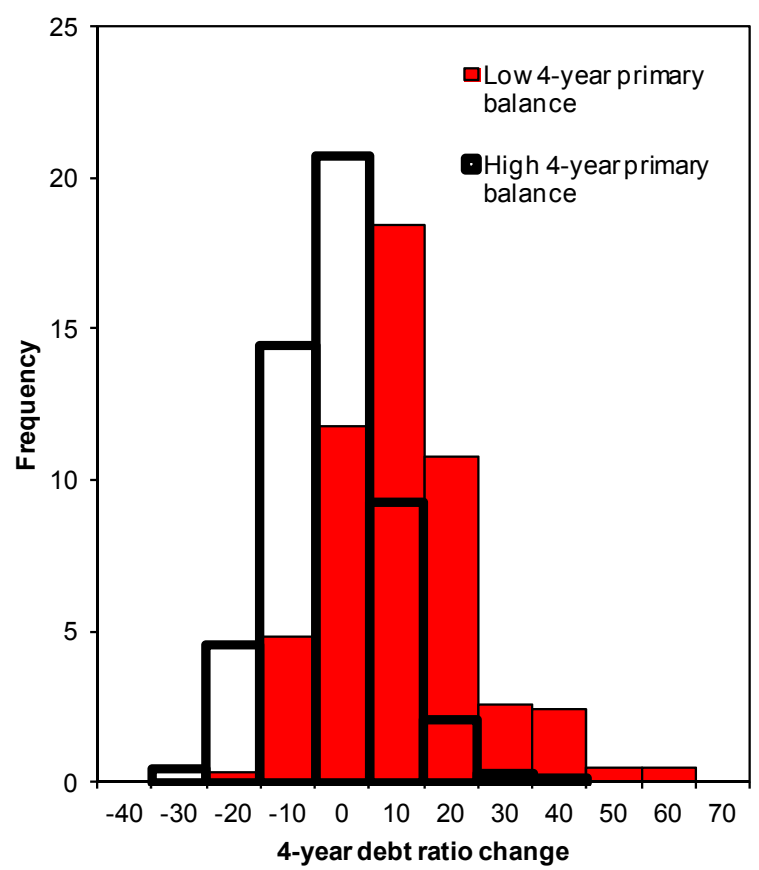

Debt dynamics do not differ visibly whether inflation is low or high...

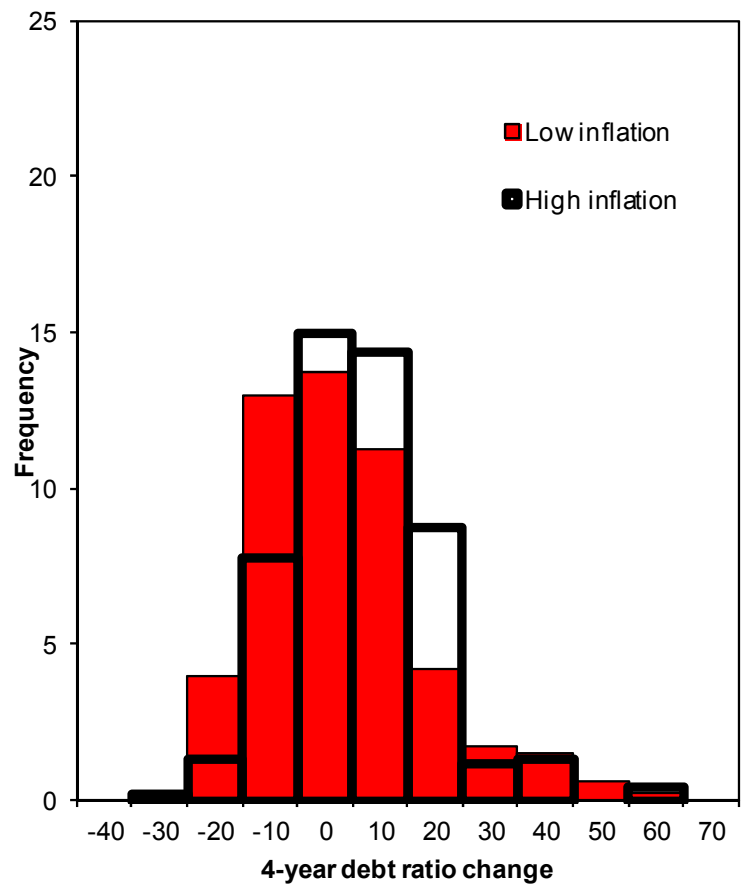

$\ldots$ and higher growth.

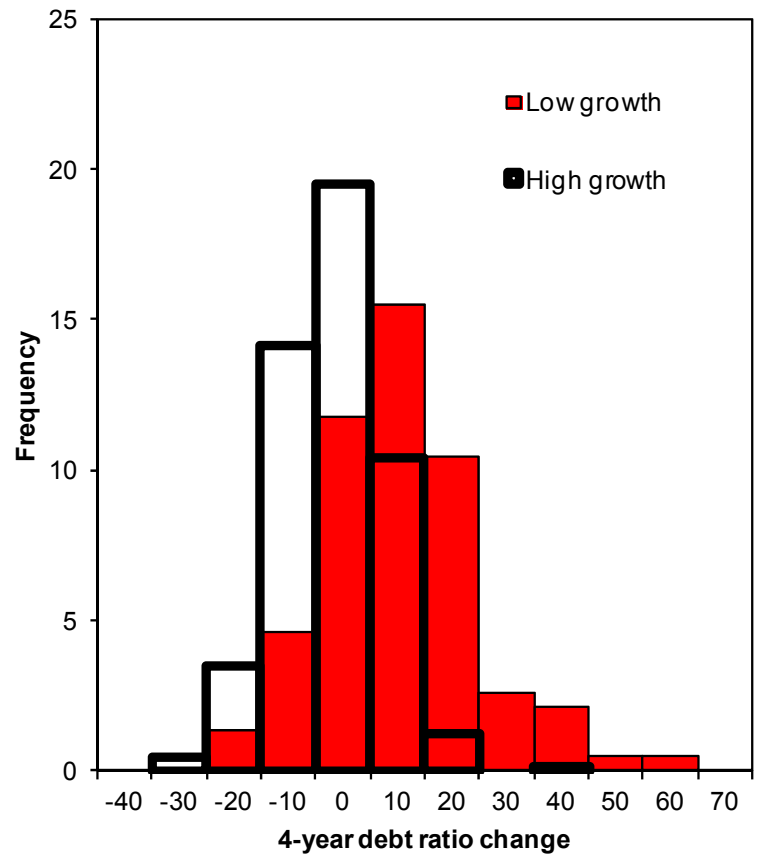

...or whether the real interest rate is low or high.

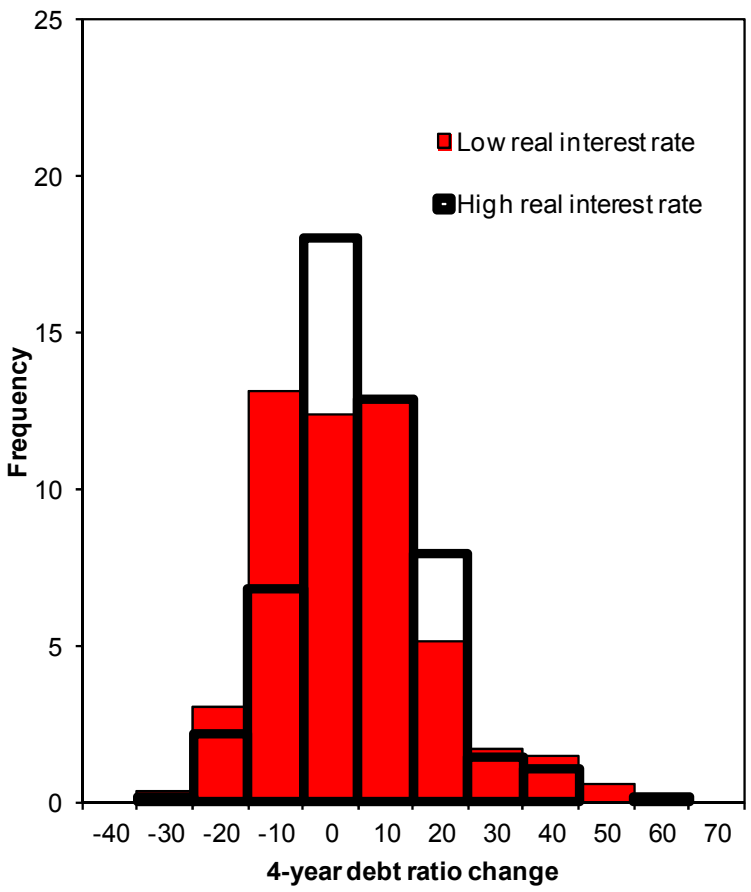

Sources: IMF World Economic Outlook; and IMF staff calculations.

Note: Each panel shows two densities of debt ratio changes where primary balances, growth rates, rates of inflation, and real interest rates are below or above their country median. 
Figure 3. Contribution to Annual Debt Ratio Reductions

(Percent of GDP)



Sources: IMF World Economic Outlook; and IMF staff calculations.

However, fiscal policies and growth are not independent. As the simulations in the next section explore in some detail, growth affects the primary balance through automatic stabilizers. ${ }^{11}$ At the same time, fiscal multipliers link changes in the fiscal balance back to growth. Fiscal effort can also affect interest rates, with knock-on effects on both growth and debt-dynamics. Last but not least, the growth environment can influence the political economy surrounding fiscal consolidations.

On average, debt reductions tend to be larger when growth rates are high and interest rates are low. While the average annual reduction in debt is 3.4 percent of GDP when growth is high and interest rates are low, it is only 1.7 and 2.4 percent of GDP, respectively, when growth is lower or interest rates are higher (Figure 4). Fewer debt reversals occurred in a challenging environment of moderate growth and high interest rates ( 7 percent of 127 debt reduction spells), and the declines were more gradual (1 percent of GDP per year). Periods of high growth are defined as four years of growth above 2 percent(allowing for one exceptional year), which is the average projected growth rate for advanced economies from 2013 to 2018 , whereas moderate growth is defined as between 0 and 2 percent.

\footnotetext{
${ }^{11}$ Another complication is that when growth is accompanied by asset price booms, it can improve both headline and structural balances, making the assessment of both fiscal space and stance more complicated.
} 
Debt Ratio Changes Conditional on Growth and Interest Rates
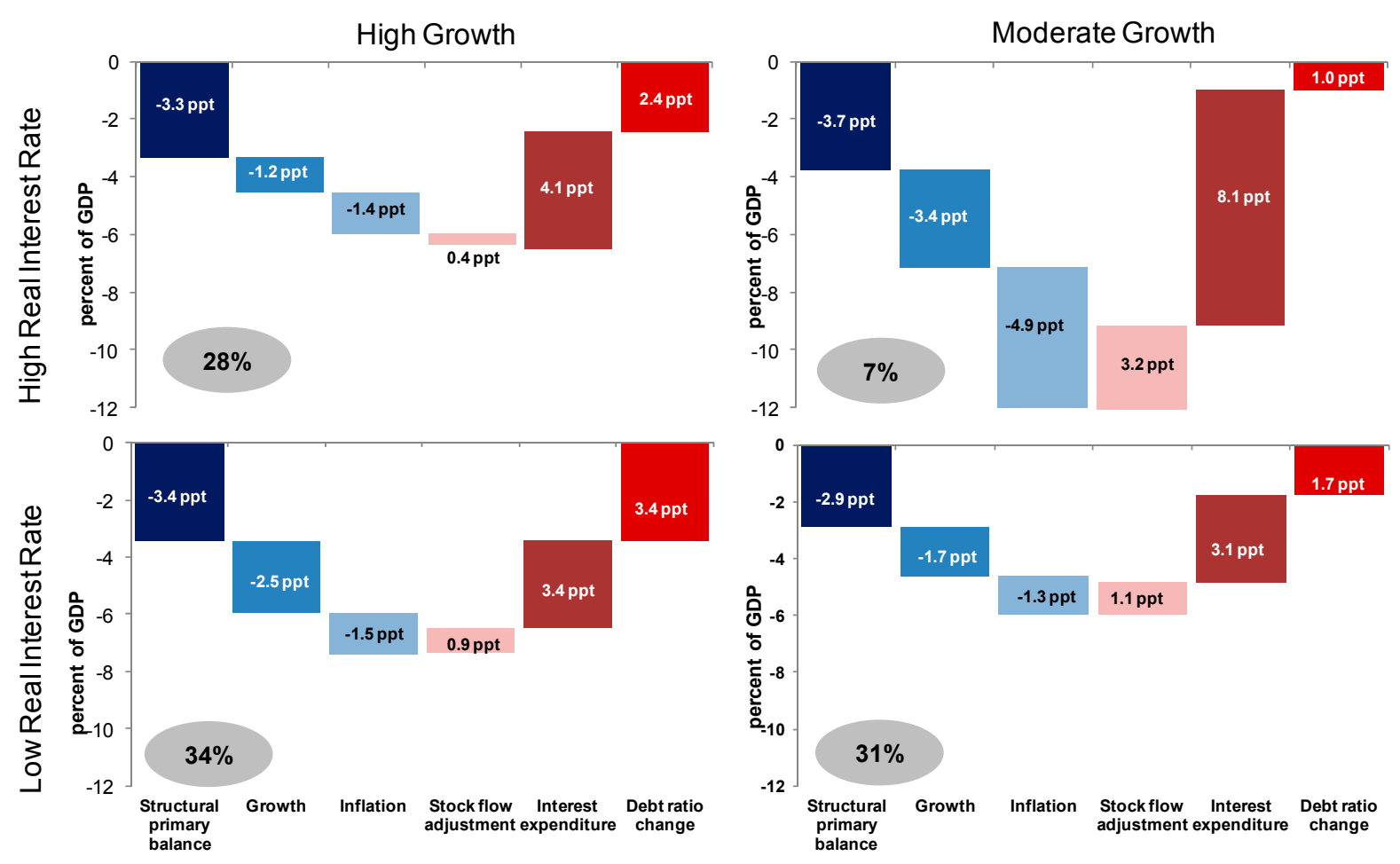

Sources: IMF World Economic Outlook; and IMF staff calculations.

Indeed, fiscal effort is more likely to be successful when growth is stronger. Only 26 percent of all fiscal consolidation spells - defined as a large adjustment in the cyclically adjusted primary balance $(\mathrm{CAPB})^{12}$ - are successful in reducing debt levels when growth is below median. When growth is above median, the success rate increases to 41 percent. Here, success is defined as at least a one-year overlap between a consolidation spell and a debt reduction spell-significant consolidation may eventually lead to a fall in debt, even if there are spells within the consolidation period that do not see a decline in debt ratios (Annex I.a). There are also fewer attempts to consolidate when growth is below the median-only about one-third of consolidations take place when growth is below the median. Similar findings hold when, instead of relying on CAPB changes, consolidation episodes are identified by policy intentions (based on contemporaneous policy documents) in order to control for the potential errors in cyclical adjustment, including possible incidences of reverse causality in CAPB measures (Annex I.b). ${ }^{13}$ This suggests that the association of higher growth with larger debt reductions,

\footnotetext{
${ }^{12}$ As in IMF (2010a), here consolidation spells are identified by a cumulative improvement in the CAPB of more than 5 percent of GDP, for episodes lasting at least three years. In a given episode the CAPB should not be reversed by more than 1 percentage point from one year to the next.

${ }^{13}$ Using the Devries and others (2011) dataset of fiscal consolidation, one finds that while fiscal efforts under low growth are more ambitious (1.2 versus 0.8 percent of GDP in measures), they result in smaller improvements of
}

(continued...) 
given CAPB improvements described above, goes beyond the simple denominator effect. Nonetheless, while there is some evidence that it is easier to improve structural balances in high-growth environments, improvements also occurred under low growth (see Annex IV).

\section{B. The Mechanics: Growth, Fiscal Policy, and Interest Rates}

Fiscal consolidation and growth are critical to improving the debt ratio, but economic conditions and fiscal policy interact in complex ways. Changes in the debt-to-GDP ratio can be decomposed into three contributing factors: (i) the interest-GDP growth rate differential; (ii) the primary balance; and (iii) SFAs. These three factors all interact with each other (Figure 5).

- Fiscal consolidation improves the primary balance, which directly lowers the amount of funds the government has to borrow, and hence the level of debt.

- However, lower government spending and higher taxes tend to have a negative effect on growth (the fiscal multiplier), which could increase the debt-to-GDP ratio in the short run. ${ }^{14}$

- Any change in GDP will in turn affect the fiscal deficit through automatic stabilizers, thus eroding some of the fiscal effort. Together with the fiscal multiplier effects, this means that fiscal consolidation may worsen the debt-to-GDP ratio in the short run, if the starting debt levels and fiscal multipliers are high (Eyraud and Weber, 2013).

- As the health of public finances improves, interest rates can drop. ${ }^{15}$ If this happens it will further improve the budget balance as the government issues new bonds to finance the remaining deficit and old debt coming due, or because existing debt was issued at floating rates. Lower interest rates can also impact the economy: if low rates encourage investors and consumers to spend more, GDP will rise and the debt-to-GDP ratio will fall.

- SFAs can also affect gross debt. Using privatization proceeds to repay debt early can lower debt-service costs; currency depreciations can raise the burden of foreign currency debt; and bank recapitalizations invariably increase debt. Insofar as asset values, currency strength, and bank health vary with growth, SFAs are typically debt-increasing when growth is weak and debt-decreasing when growth is strong.

the primary balance ( 0.7 versus 0.8 percent) and, for observations falling into debt reduction spells, smaller declines in debt levels $(0.2$ versus 1.7$)$.

${ }^{14}$ The size of these effects also depends on various factors. Spilimbergo, Symansky, and Schindler (2009) describe how accommodative monetary policy can increase the multiplier during fiscal expansions, while IMF (2010b) and Woodford (2011) show how a policy rate close to the zero-lower-bound can worsen the economic impact of fiscal consolidation. Batini, Callegari, and Melina (2012) and Blanchard and Leigh (2013) highlight their finding that multipliers can be higher in recessions.

${ }^{15}$ Healthier public finances can impact risk premiums because investors react to the improving fiscal balance (e.g., Giavazzi and Pagano, 1996; Alesina and Perotti, 1995; Alesina and Ardagna, 2010). If risk premiums respond to debt levels, the effect of consolidation is more ambiguous, as a short-term increase in the debt ratio could further exacerbate debt levels through higher yields (Batini, Callegari, and Melina, 2012). 


\section{Figure 5. Debt Ratio and Economy}

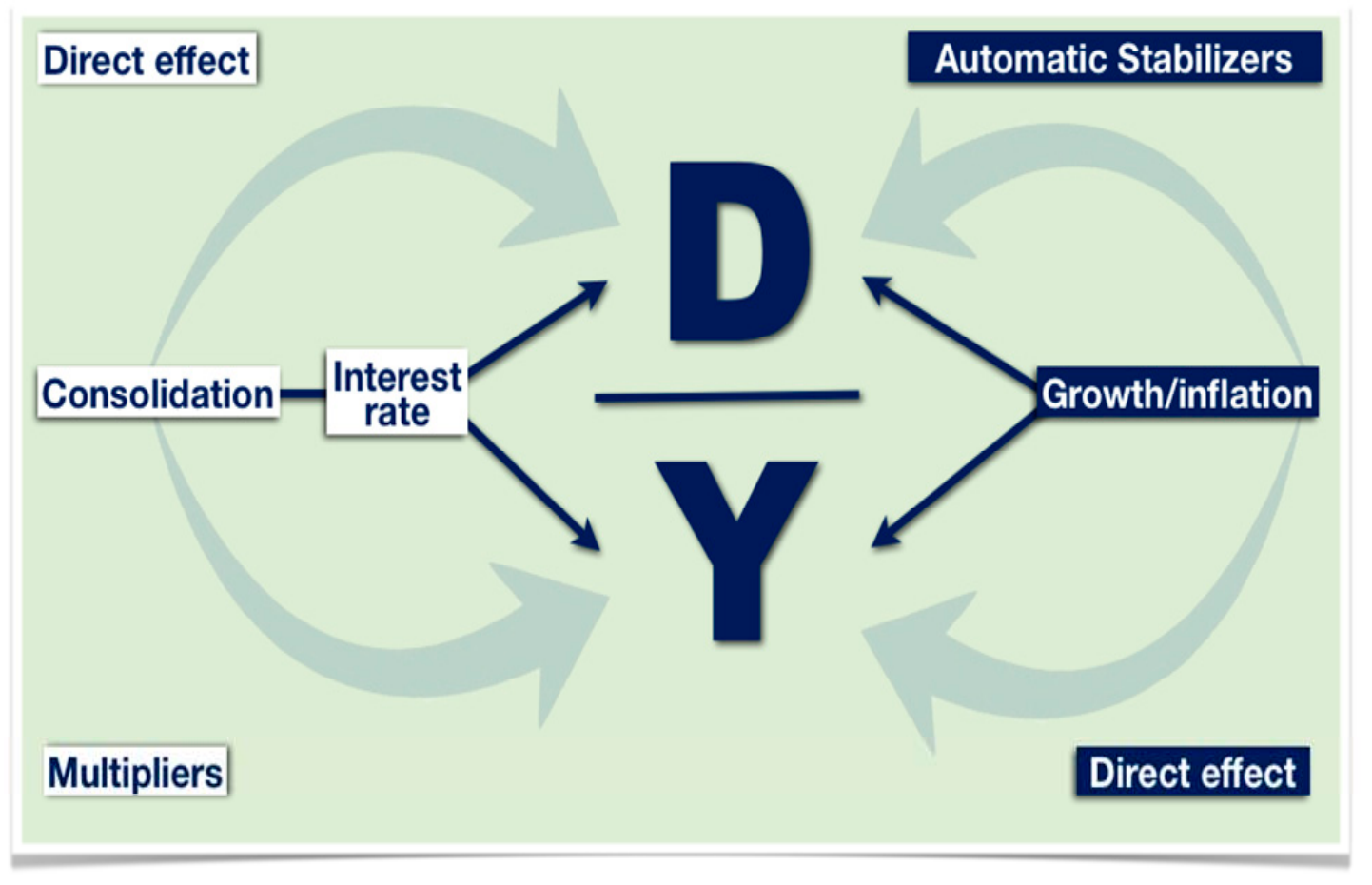

Illustrative calculations further show the importance of these factors for debt reversals. The underlying model (see Annex V) assumes that GDP evolves in line with long-term potential growth, abstracting from cyclical forces. Relative to a baseline calibrated according to euro area averages (end-2012), the speed of any debt reversal due to fiscal consolidation increases considerably if growth is more buoyant and/or interest rates are lower (Figure 6). In the simulation that takes into account the interactions discussed above, each 1 percentage point increase/decrease in growth/interest rates reduces debt by an additional 10 percentage points over 10 years. The precise outcome will vary according to the starting debt level and the assumptions made regarding the expenditure response to higher growth. ${ }^{16}$

Fiscal policy and growth also interact over the long run. In certain circumstances, discretionary policy changes can affect long-run potential growth. For example, DeLong and Summers (2012) argue that a process of hysteresis links the short-term cycle to the long-term trend, implying more persistent fiscal policy effects. One channel at work is that protracted periods of unemployment can lead to skill losses that reduce productivity and, thereby, potential growth. Such declines in potential growth, in turn, can lead to an unwanted deterioration in the

\footnotetext{
${ }^{16}$ For example, simulations in IMF (2013) find that, with revenues at 40 percent of GDP, a 1 percentage point increase in long-term growth would result in an improvement of 0.4 percent of GDP in the structural fiscal balance if all additional revenue were saved. The combination of this and the denominator effect would help a country with a debt ratio of 100 percent of GDP reduce its debt by 30 percent of GDP in 10 years.
} 
structural balances despite the apparent absence of discretionary policy (Mauro and others, 2013).

\section{Tradeoffs}

Faster fiscal adjustment comes with tradeoffs. Frontloading a fiscal consolidation to achieve a given debt reversal within a certain time span will have a larger up-front growth cost than would a more gradual approach, because of the multiplier effect. However, the gradual approach requires higher levels of the primary balance later in the period to compensate for the delayed improvement in primary flows (Figure 7). ${ }^{17}$ State-dependent multipliers in downturns exacerbate the economic cost of the up-front strategy, if the up-front adjustment were to tip the economy into a recession, whereas potential interest bill gains from credibility effects would lower the level of primary balance needed. This suggests that short-term pain now must be weighed against the economic and political difficulties of generating higher overall primary surpluses for a prolonged period (see Zeng, 2013, for a discussion of the difficulties in sustaining a high primary surplus).

Figure 6. Factors Driving Debt Reversals

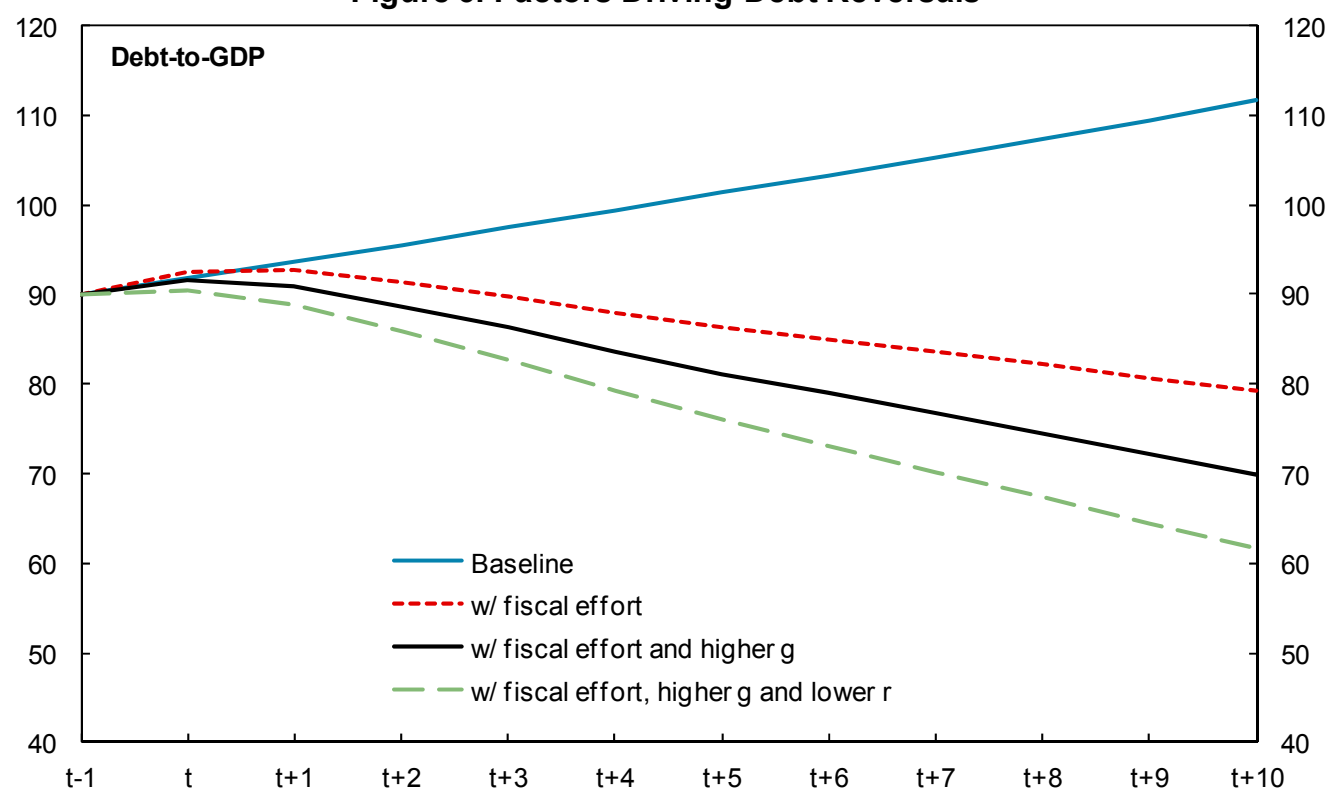

Assumptions:

Baseline real growth: 1.2 percent (excluding drag from risk premium). Underlying interest rate: 2 percent. Starting debt-to-GDP ratio: 90 percent. Maturity (average): 7 years. Fiscal multiplier: 1 and persists for 4 years.

Credibility effect: 15 bps per 1 percent of GDP adjustment.

The structural primary balance is adjusted by 2 percent of GDP in $t$ and 1 percent more in $t+1$. Higher growth and lower interest scenarios increase/decrease baseline rates by 1 percentage point respectively.

\footnotetext{
${ }^{17}$ Under the assumption of a constant multiplier, the cumulative output loss is the same in either scenario. When multipliers are state-dependent ( higher in deep recessions), the output loss from up-front consolidation would be larger.
} 
Figure 7. Growth and Primary Balance Paths for Achieving a Given Debt Reduction

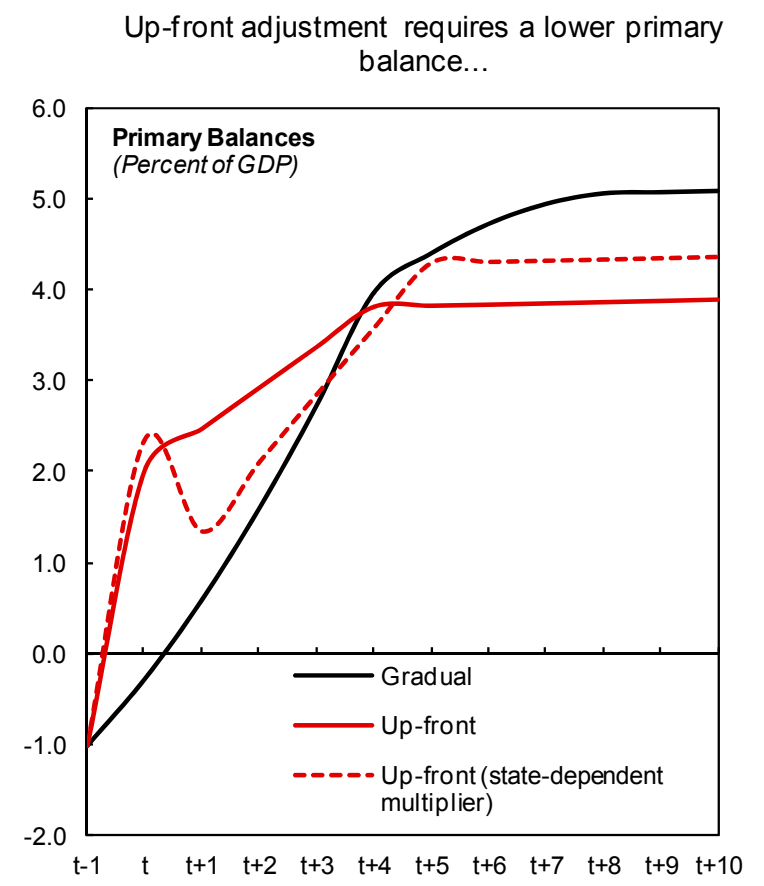

...but with more pronounced short-term costs (especially if multipliers are state-dependent).

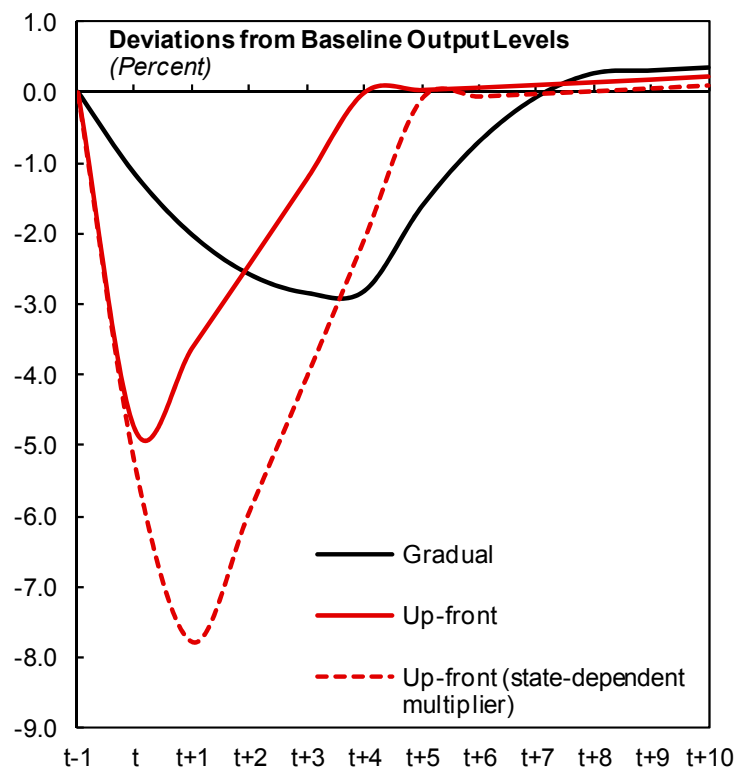

\section{Assumptions:}

Baseline real growth: 1.2 percent (excluding drag from risk premium). Starting debt-to-GDP ratio: 90 percent.

Fiscal multiplier(regular) : 1 and persists for 4 years

Fiscal multiplier(state-dependent): 1.5 , peaks in $\mathrm{t}+1$ and persists for 5 years

Underlying interest rate: 2 percent.

Maturity (average): 7 years.

Credibility effect: 15 bps per 1 percent of GDP adjustment.

The structural primary balance is adjusted in order to meet a 60 percent of GDP target by $t+10$ under two strategies: gradual adjustment over 5 years (total adjustment needed is 6 percent of GDP) or up -front adjustment (total adjustment needed is 4.8 percent of GDP with regular multiplier and 5.3 percent of GDP with state-dependent multiplier).

Another trade-off centers on the multiplier effect and credibility. While fiscal consolidation comes at the cost of initially lower economic activity, it can help reduce sovereign risk premiums, relative to a counterfactual in which there is gradual or no adjustment. In general, the balance will depend on the urgency of restoring market credibility, as well as on factors such as the size of the output gap, openness, and the simultaneity of the fiscal effort elsewhere (as aggregate multipliers are larger for synchronized consolidations, because of the weaker offset from external demand). In some cases, excessive front-loading, by undermining social and political cohesion, might hurt rather than help market confidence.

Both the multiplier effect and the credibility effect have important implications for debt dynamics. To illustrate the underlying mechanics, Figure 8 shows a modified baseline scenario where debt dynamics include a stronger risk premium effect from reductions in the debt level as the starting level of the debt ratio is higher. ${ }^{18} \mathrm{~A}$ fiscal consolidation over two years pushes up the debt ratio due to the multiplier effect, before leading to a gradual reduction in debt levels. The risk premium linked to the degree of fiscal effort is made stronger, which generates a

\footnotetext{
${ }^{18}$ Batini, Callegari, and Melina (2012) show that up-front consolidation can worsen the debt level relative to a gradual effort and that this effect is exacerbated if risk premiums are linked to the debt level. In their simulation, multipliers vary according to the cycle.
} 
larger credibility effect that helps bring down debt more rapidly. ${ }^{19}$ The credibility effect assists debt reduction through two channels: lowering the interest bill of the sovereign (direct effect) and stimulating economic activity by also lowering private-sector borrowing costs (indirect effect through lower output losses) (Figure 8).

Figure 8. Debt Reversals with Credibility Effects

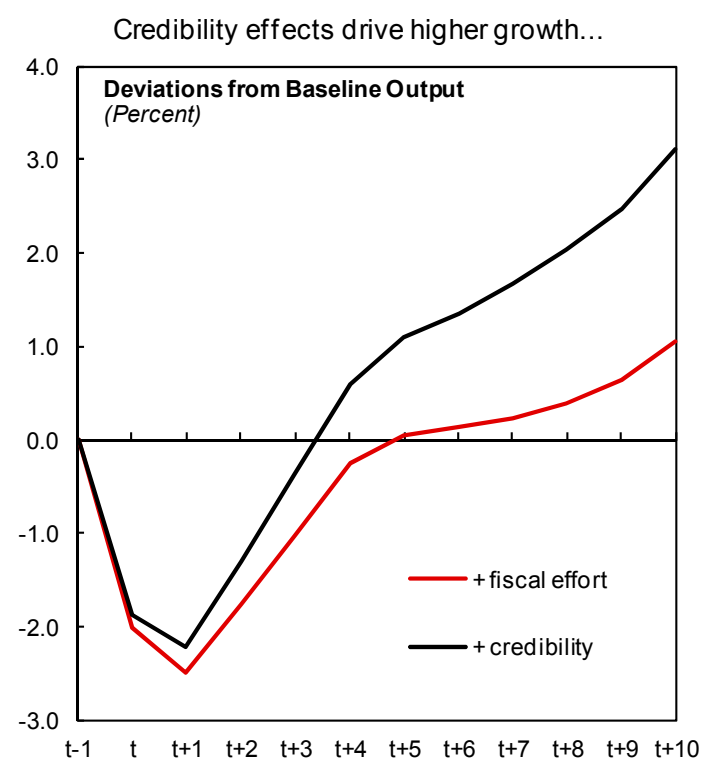

Assumptions:

Baseline real growth: 1.2 percent (excl.drag from risk premium).

Starting debt-to-GDP ratio: 130 percent (closer to D_max of 170 ).

Fiscal multiplier: 1 and persists for 4 years.

Baseline primary balance: -1 .

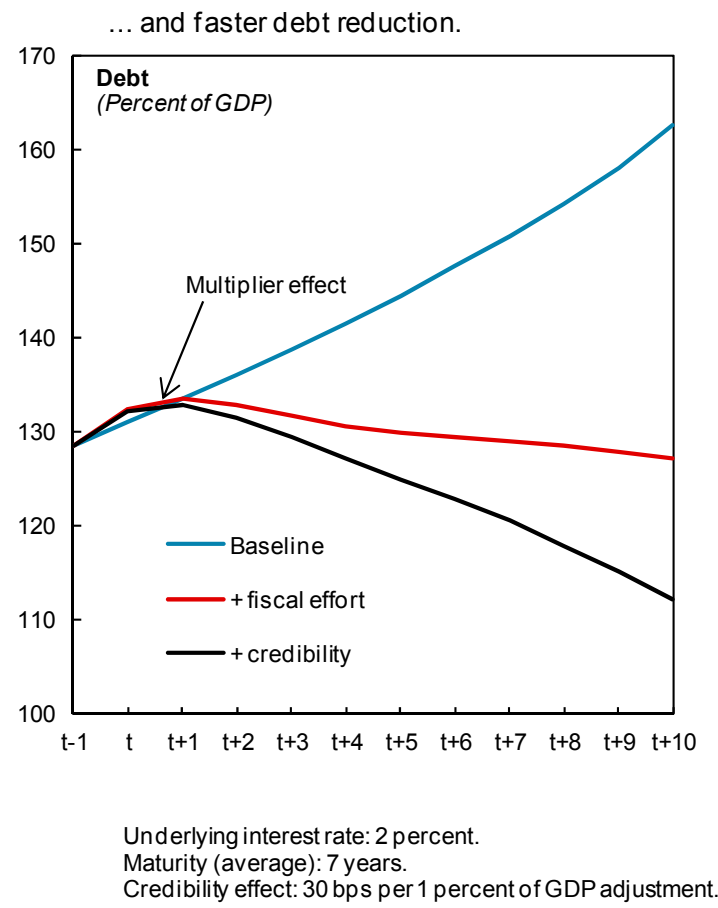

The structural primary balance is adjusted by 2 percent of GDP in t and another 1 percent of GDP in $t+1$.

\section{Large Debt Reversals in the Past}

Some of the largest debt reversals among advanced economies since 1980 started in difficult economic conditions. The stylized facts and simulation results in the previous sections caution that debt reversals in times of low growth can be difficult. But does this mean that they are impossible to achieve? The answer depends on the circumstances. For example, when sovereign risk premiums are very high and market access is in doubt, debt will have to be reduced even under adverse circumstances, a fact also reflected in the past episodes discussed below.

Since 1980, a total of 26 large debt reduction episodes of varying lengths occurred in 20 advanced economies (Figure 9, Annex III). These episodes focus on reductions in the debt-to-

\footnotetext{
${ }^{19}$ Conceptually, the fiscal effort can have a larger impact if the risk premium reacts to the fiscal balance. Linking the risk premium to the expected primary deficit, Corsetti and others (2012), we find that up-front fiscal consolidation is less detrimental to economic activity, and in cases of severe fiscal stress and constrained monetary policy it may even be expansionary.
} 
GDP ratio in excess of 5 percentage points,${ }^{20}$ from debt levels that started above 50 percent of GDP. All episodes featured fiscal consolidation, but the size of the underlying fiscal action did not influence their selection. Notable characteristics include these:

- Historical background. The majority of the episodes started in the 1990s, reflecting, among other things, growth-supported consolidations in the Anglo-Saxon economies, the targeted improvement of public finances in Europe in the run-up to the introduction of the euro, and the large adjustments following the Nordic financial crises.

- Size. The average reduction in debt across these episodes was 26 percent of GDP, from an average starting point ( 79 percent of GDP) similar to current levels. Out of the 26 episodes, 22 resulted in debt reductions of at least 11 percent of GDP.

- Duration and speed. The average episode spanned 8 years, with the shortest one being New Zealand's in 1986-88, coinciding with double-digit inflation, and the longest one being Ireland's in 1987-2007, where growth averaged 5.7 percent. The average pace of debt reduction was around 3 percentage points of GDP per year.

Not surprisingly, growth conditions and fiscal consolidation were the main drivers behind these large debt reversals. Figure 9 shows the major debt reduction components - structural primary balances, real GDP growth (cyclical and potential), and real effective interest rates-for the 26 episodes. Although the debt reductions vary by duration (ranging from 3 to 20 years), by size (from 6 to 84 percent of GDP) and by type of economy (large, small, European, and other advanced), the broad pattern is captured by the average column on the extreme right. The average contribution of the structural primary balance was about equal to the total size of debt reduction. The debt-reducing contribution of growth largely offset the debt-increasing contribution of the interest bill. In other words, the typical growth-interest rate differential was close to zero (see Annex III for a detailed table of these episodes). The data suggest that high structural primary surpluses occurred during periods of both high and low growth. In fact, to the extent that any correlation is visible, it seems that countries generated higher primary surpluses when the economic environment was weaker, perhaps to compensate for low growth (Figure 10). It should be noted, however, that average growth was below 2 percent in only three of the 26 episodes, which cautions that budget surpluses might have occurred mostly beyond a minimum level of growth. ${ }^{21}$

\footnotetext{
${ }^{20}$ As the findings below indicate, the actual reductions were much larger for most countries.

${ }^{21}$ Outside the identified debt reduction periods, growth remained below the 2 percent threshold in 25 percent of the years since 1980. This compares to 19 percent during debt reduction episodes.
} 
Figure 9. Components of Major Debt Reductions in Advanced Economies Since 1980

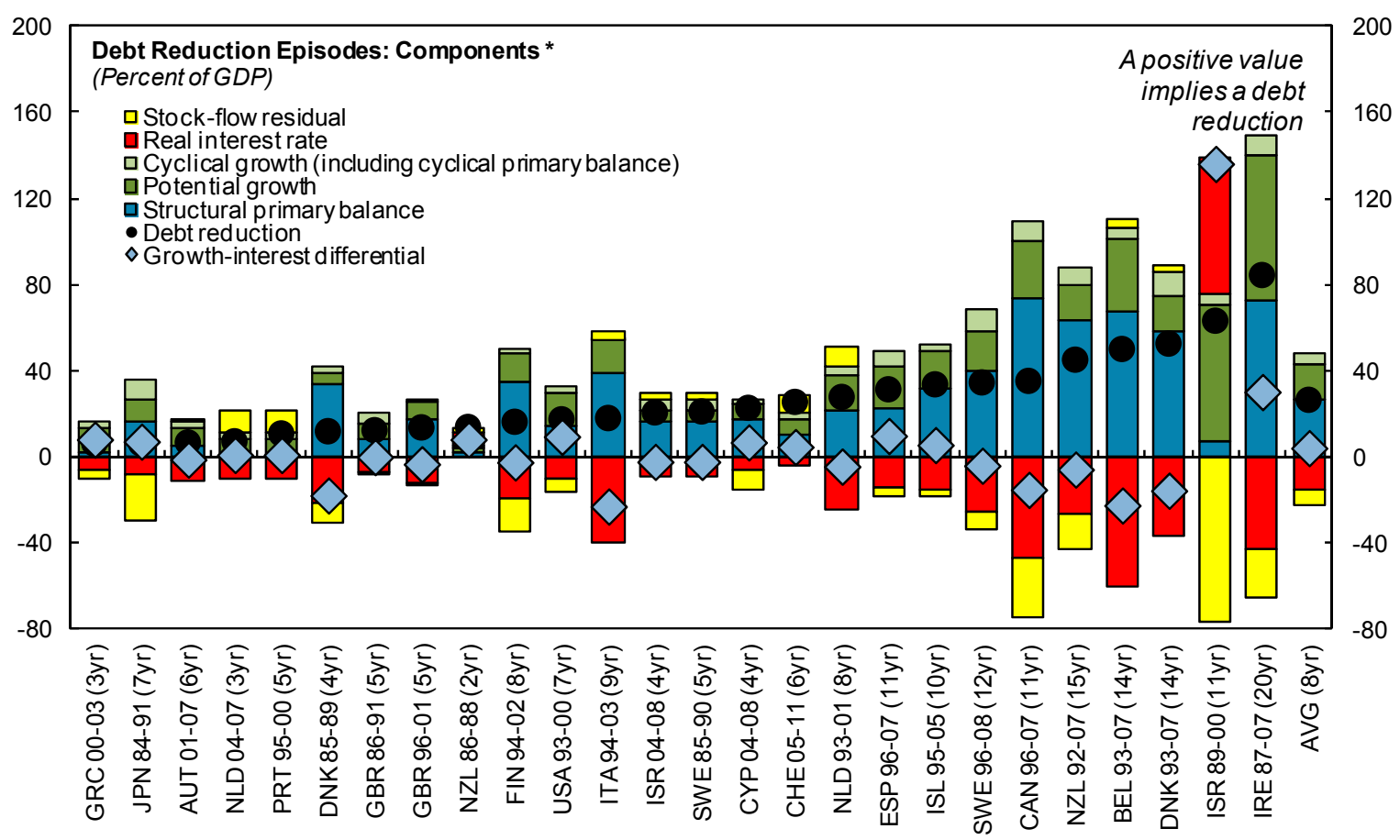

Sources: IMF World Economic Outlook; and IMF staff calculations.

* Total contribution of components over entire debt reduction period (length of period in brackets).

Figure 10. Real GDP Growth, Structural Primary Balance, and Size of Initial Debt 1/ -- Advanced Economies Since 1980 --

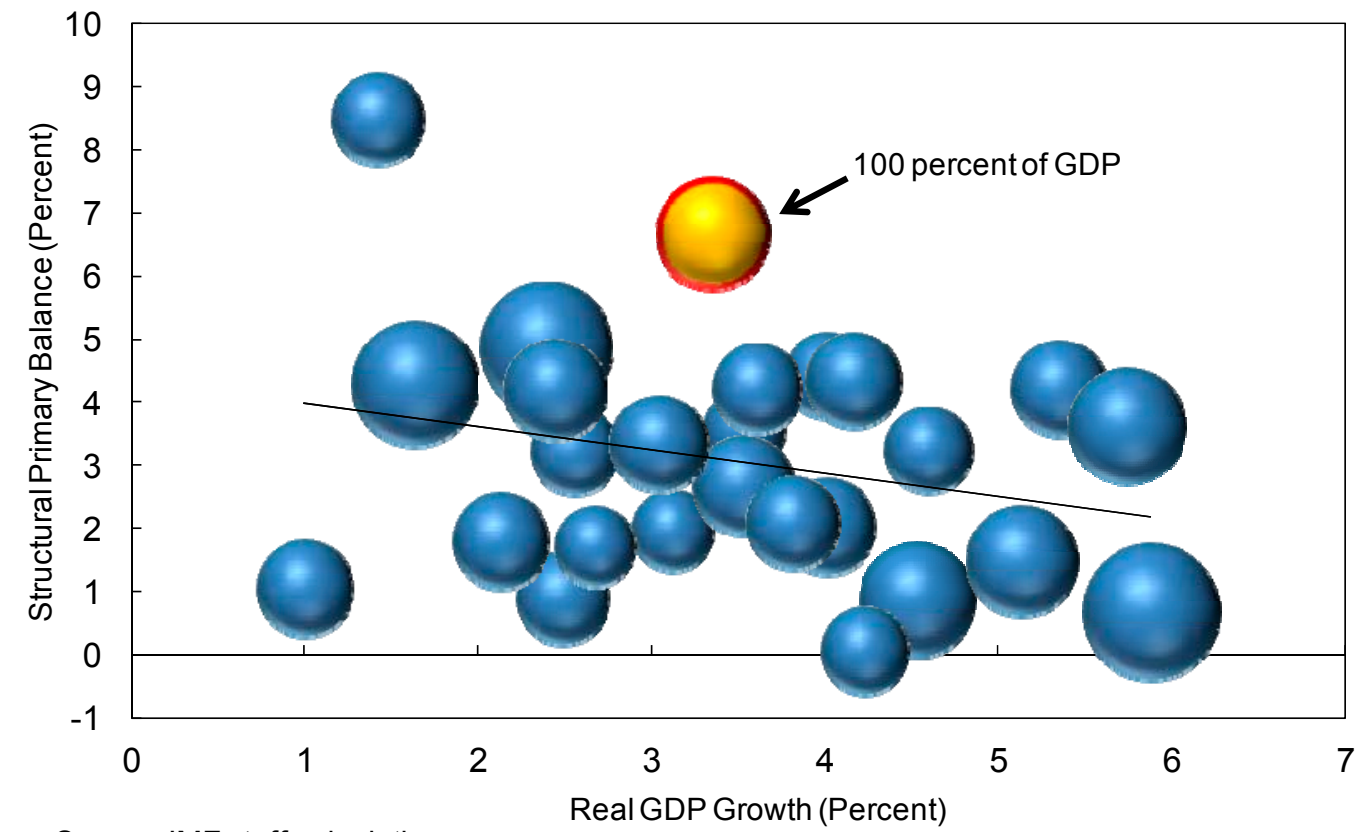

Source: IMF staff calculations.

1/ Real GDP growth and primary balance data are calculated as averages observed over the debt reduction period. 
Some of the largest debt reductions were achieved when initial conditions were particularly difficult (Figure 11). ${ }^{22}$ Over the period 1989-2007, seven advanced economies (Austria, Belgium, Denmark, Iceland, Israel, Netherlands, and New Zealand) managed to achieve debt reductions averaging about 40 percent of GDP, in spite of initially high debt levels (averaging 90 percent of GDP), and zero or modest growth (averaging 0.3 percent). In another important episode-Italy's during 1994-2003 — debt was reduced by 18 percentage points from 122 percent of GDP, despite economic growth averaging a modest 0.7 percent in the three years prior to the debt reduction and $1 \frac{1}{2}$ percent during the debt reduction. These episodes suggest that when countries try hard, large debt reversals can be achieved even in a low-growth environment.

A closer look at the underlying dynamics reveals that, while initial conditions were difficult, a number of factors helped to bring debt-ratios down eventually. In particular, external demand and falling interest rates provided crucial growth support as fiscal consolidation efforts picked up (Figure 12):

- External demand conditions improved in the lead-up to debt reductions. The typical episode was characterized by gradual real exchange rate depreciation and rising exports three years before debt ratios began to reverse downward (period $t$ in Figure 12). ${ }^{23}$ The exchange rate stabilized as debt began to fall, but export value growth remained around 10 percent until $t+2$ before moderating.

- Falling short-term rates suggest supportive monetary policy, leading a fall in longer-term rates starting in $t-2$ ahead of the drop-in debt ratios. The reduction in T-bill rates started as early as $t-4$ and continued, at a declining rate, throughout the observation period for most episodes. Importantly, short-term rates fell from higher levels, which meant that monetary support was unconstrained by the zero lower bound. Previous analyses, such as IMF (2012), have also highlighted the importance of supportive monetary policy in reducing high public debt ratios.

- The start of the typical debt reduction episode coincided with a pick-up in growth. Real GDP growth picked up by almost 2 percentage points in the first year of falling debt. This followed the strengthening of the external environment and falling interest rates, and it came with a rapid increase in domestic demand starting in $t$.

\footnotetext{
22 "Initial conditions" refers to the year in which the debt-to-GDP ratio peaked.

${ }^{23}$ The averages hide larger individual exchange rate movements. In 24 of the 26 debt reduction episodes, a real effective exchange rate (REER) depreciation was observed at some point during the four years preceding the start of the debt reduction, with the depreciation exceeding 10 percent in 16 of them. The average cumulative REER depreciation for the 24 episodes was 13 percent, over half of which was reflected in a nominal effective exchange rate adjustment. The nominal effective adjustments, in turn, came by way of both abrupt changes/devaluations (such as in Finland, Italy, Ireland, Portugal, Spain, the United Kingdom, and Sweden - the latter two corresponding to the 1992 exit from the European Exchange Rate Mechanism) and more gradual depreciations in the context of floating exchange rates (as in Belgium, Denmark, and Netherlands).
} 
- Fiscal effort strengthened as growth picked up. While the structural primary balances were positive on average in the years preceding the debt peak, they improved significantly in $t$ and continued to strengthen as debt fell.

- Inflation did not contribute to the large debt reversals in the sample. In fact, inflation fell and would have led to increasing debt ratios, all else equal. 
Figure 11. Size of Debt Reduction vs. Initial Levels of Key Variables * -- Advanced Economies Since 1980 --

Many debt reduction episodes started when real interest rates were elevated.

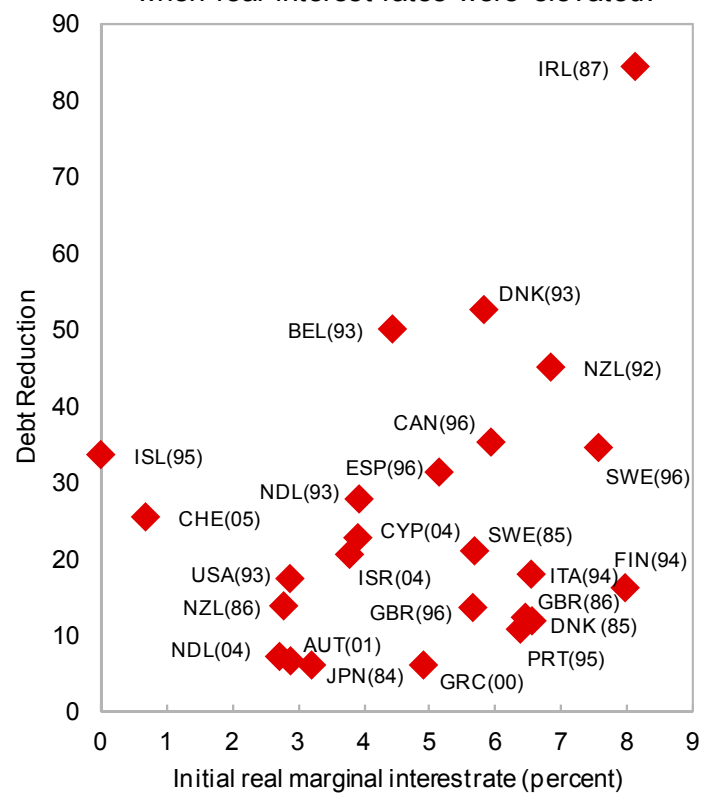

Real GDP growth was often low at the outset of debt reduction episodes.

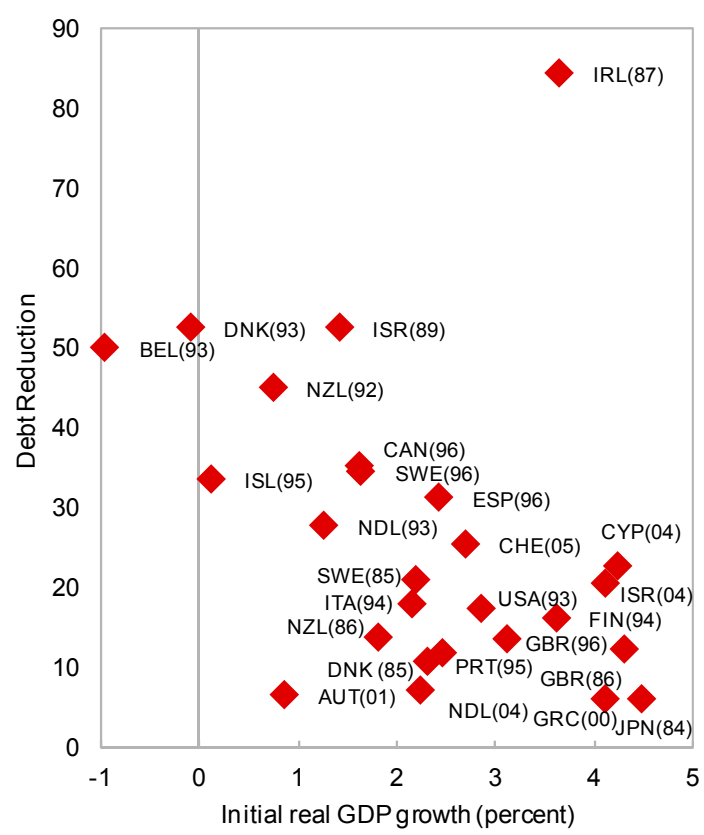

Higher initial debt ratio is associated with larger debt reduction.

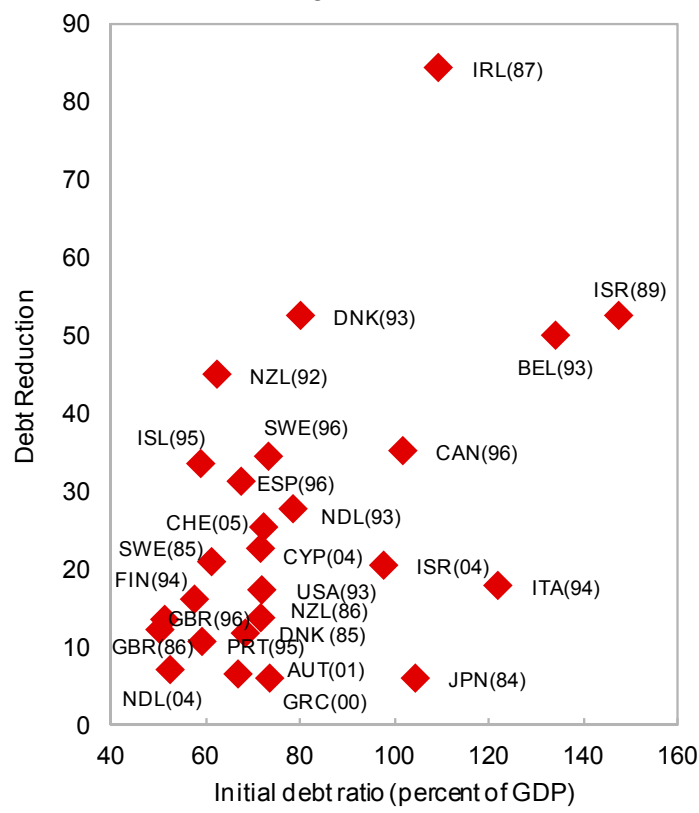

Larger debt reductions are associated with a higher initial structural primary surplus.

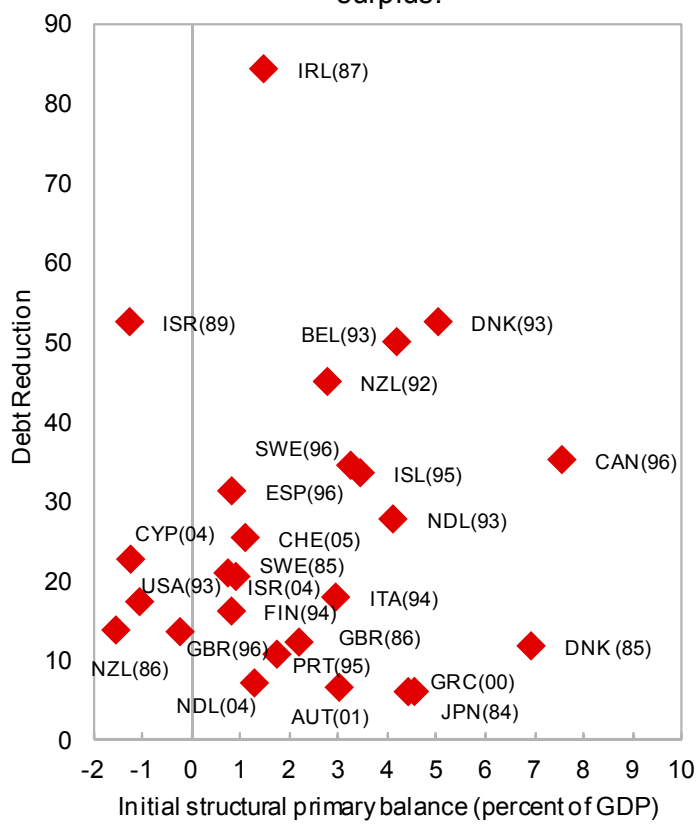

Source: IMF staff calculations.

* Year in brackets refers to the start of the debt reduction period. 
Figure 12. Evolution of Key Variables through Deficit Reduction Episodes -- Advanced Economies Since 1980 --
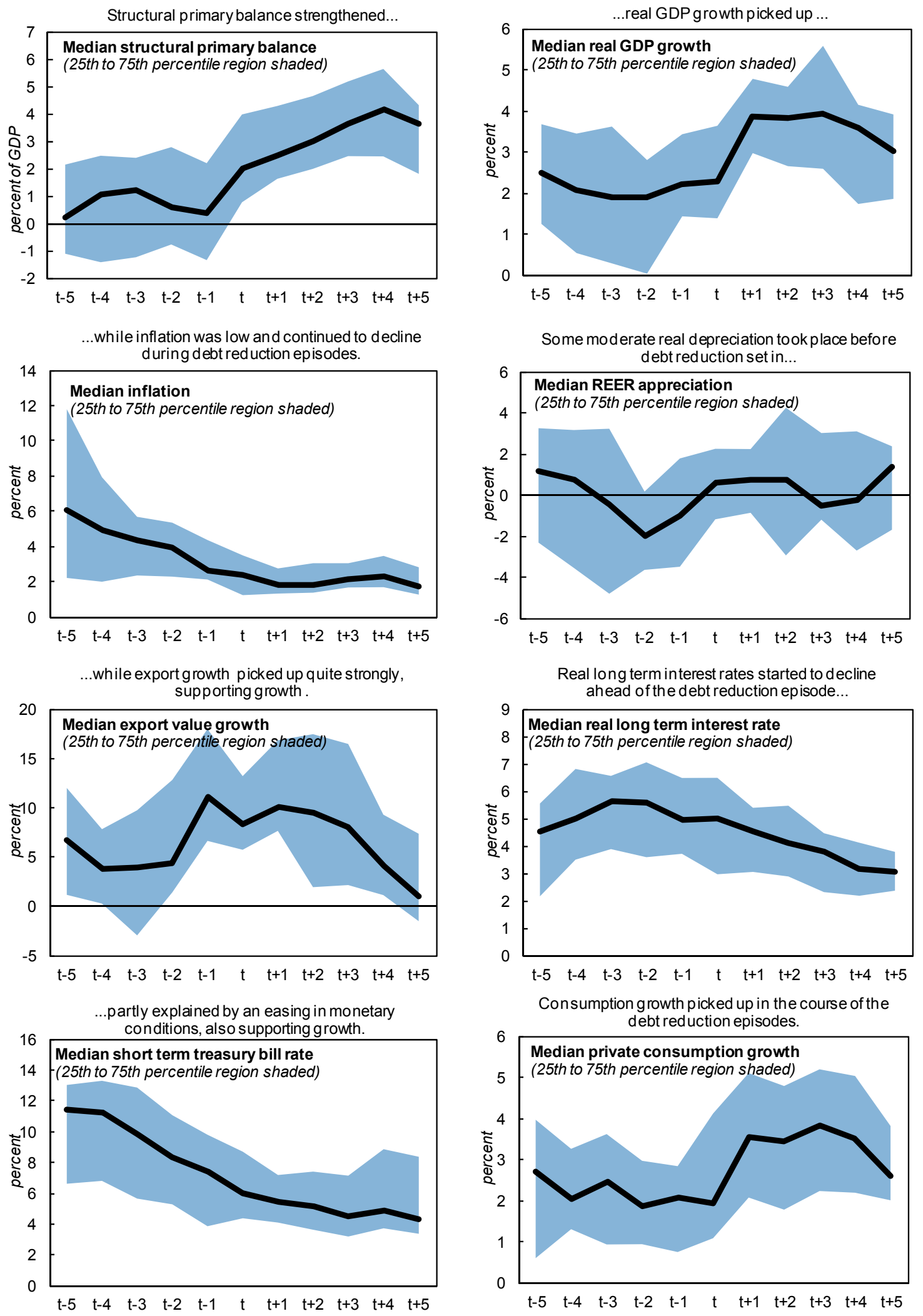

Source: IMF staff calculations. 
The foregoing suggests that an improving growth environment was an important feature of successful debt-reduction experiences. The fact that growth did not decline in the year before the debt peak - a year of relatively strong fiscal consolidation — suggests that supportive monetary policy, falling long-term rates, and the healthy external environment likely played a part in reducing the size of the fiscal multiplier. Moreover, a reasonable argument can be made that the politics of the fiscal effort in that year will have been supported by the improving outlook for economic activity. ${ }^{24}$ Eventually, lower borrowing costs and the rapid pick-up in real private consumption helped drive down debt ratios and also mitigated the impact of the fiscal adjustment which started in $t$. Structural primary balances peaked four years into debt reduction.

The findings are robust even when looking at subsamples of the main debt-reduction episodes (Figure 13): ${ }^{25}$

- EMU convergence and Maastricht criteria. Seven out of the 26 sampled debt reduction episodes occurred in the run-up to the EMU accession (Belgium, Cyprus, Greece, Italy, Netherlands, Portugal, and Spain). This raises the question whether the drop in interest rates noted for the full sample was driven by prospective euro accession. However, while the future euro area members saw a somewhat earlier and more pronounced drop in long-term rates than others, rates also dropped during the other debt reduction episodes in the sample.

- $\quad$ Durable debt reductions. The stylized facts discussed for the full sample also hold when looking only at more durable debt-reduction episodes (more than 5 years of falling debt) and debt reductions in large economies. ${ }^{26}$ For the more durable debt-reduction episodes, there is a more pronounced impact on growth from the large consolidation at the start of the episode, which coincides with a temporary drop in export growth.

- $\quad$ Large economies. In large economies, fiscal consolidation (improvement in structural primary balance) starts from a lower base than elsewhere, but the pattern of growth and debt largely follows the one in the full sample. The growth in external demand before the debt peak is larger than for the entire sample.

\footnotetext{
${ }^{24}$ Cottarelli and Jaramillo (2012, p. 7) note that markets have a strong focus on near-term growth prospects and hence a better growth outlook could also support fiscal adjustment through lower borrowing costs.

${ }^{25}$ See Annex II for a description of the country coverage of the different subsamples.

${ }^{26}$ These criteria are relevant for some euro-area countries in the current environment.
} 
Figure 13. Evolution of Key Variables in Subsamples

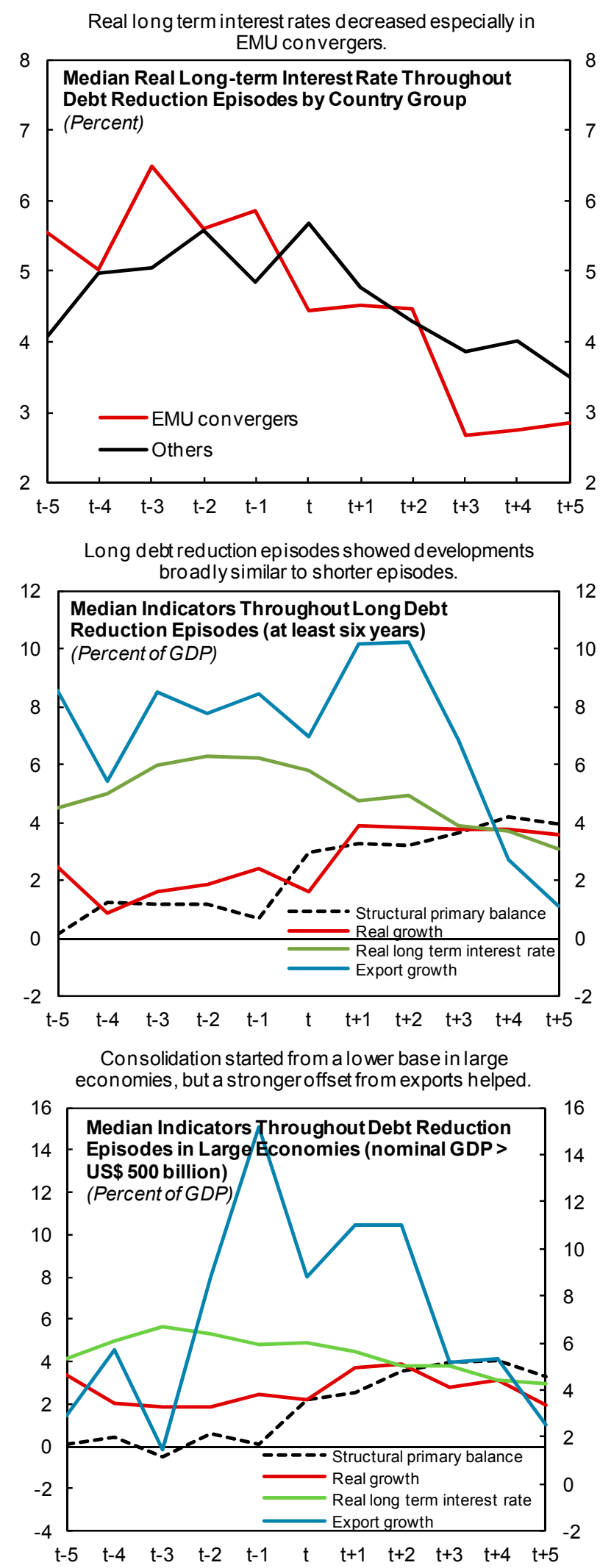

Source: IMF staff calculations. 


\section{DeAling With DEBT When GROWTH is LOW}

Dealing with high debt is not easy when growth is low. The advanced economy experience with debt reduction - with many episodes starting under very adverse circumstances — suggests that the task ahead is achievable, although the current and expected growth outlook is probably tougher than in past episodes. In the absence of growth, the burden of adjustment will shift to fiscal consolidation. While this can work, it comes at a larger cost to growth in the short-term and may initially increase the debt-to-GDP ratio because of fiscal multipliers effects (Section II). Given the moribund credit markets, the zero lower bound on nominal interest rates, and the still sizable output gap, the expectation is for fiscal multipliers to be larger than in more normal times. Thus, in the short term at least, a faster pace of consolidation could jeopardize the goal of reducing debt and the sustainability of fiscal effort. So what are the options for fiscal policy, and could other approaches, such as inflation and privatization, provide support?

\section{A. Fiscal Policy}

If multipliers are large, getting the pace of fiscal adjustment right is critical. Fiscal consolidation can hurt growth and exacerbate debt levels in the short run; therefore, where financing allows, adjustment should be conducted at a pace that balances the need to improve structural primary balances against the need to not undermine the recovery. ${ }^{27}$ Where sovereign market access is threatened and risk premiums are approaching prohibitive levels, smoothing the required consolidation may not be feasible and there might be a need to establish credibility through front-loaded adjustment, keeping in mind that too much frontloading may be "selfdefeating." However, given the uncertainty about the point at which a country will lose market access, and the possibility of multiple equilibria, judgments about whether fiscal adjustments are excessively frontloaded will often be uncertain in practice.

Strong fiscal institutional frameworks can help. Even where countries have fiscal space, the short-run effects on growth of faster consolidation need to be balanced against the decrease in risks from lower debt levels. To avoid the loss in credibility that could come with substituting for adjustment today a promise to adjust tomorrow, the fiscal path should be embedded in a credible fiscal consolidation strategy, buttressed by strong budget institutions. To this end, institutional arrangements such as medium-term fiscal frameworks, fiscal responsibility laws, fiscal rules, and fiscal councils are important. For example, institutional strengthening in the European Union - involving reforms agreed under the "Fiscal Compact" and the "six pack"can help anchor medium-term fiscal credibility. ${ }^{28}$

The composition of adjustment also matters. On the expenditure side, cutting investment spending or support for the most vulnerable will hurt growth prospects more than reducing non-

\footnotetext{
${ }^{27}$ The fact that external demand helped during the debt-reduction episodes analyzed earlier also suggests that international coordination is important in this regard. Simultaneous consolidation across many advanced economies tends to amplify the adverse effect on growth, suggesting that fiscal action should be sequenced and coordinated to reduce the size of the fiscal multiplier.

${ }^{28}$ See April 2012 and April 2013 IMF Fiscal Monitor.
} 
targeted social spending and subsidies. On the revenue side, there is a need to reduce tax expenditure, fight evasion, reduce the taxation of labor with respect to consumption, and increase property taxation (Cottarelli and Jaramillo, 2012).

\section{B. Monetary Policy}

In an environment of public sector deleveraging, monetary policy should remain accommodative, with due regard to country conditions. With fiscal consolidation acting as a drag on growth, monetary stimulus needs to be kept in place, especially in countries where the output gap remains large. This means keeping policy rates at low levels and maintaining ample liquidity, subject to inflationary expectations remaining well-anchored. If downside risks materialize, further rate reductions should be considered, where possible, as well as additional unconventional measures, especially in economies where policy rates are near the zero lower bound. In regions where the monetary policy transmission mechanism is broken, for instance due to a weak banking system, this should be addressed.

\section{Privatization}

In the past, the privatization of public assets has figured prominently in debt-reducing strategies, including in Fund-supported programs. Privatization can help lower public debt through two channels. First, if properly executed, the sale of government assets may help boost overall productivity, raising potential growth. Second, privatization can affect the SFA factor in public debt dynamics if it is used to pay down debt. In the past, proceeds from privatization have been sizable in advanced economies. For instance, Portugal collected about 16 percent of GDP in privatization revenue over 1996-2000; Italy collected 7 percent over 1997-2001; and Greece and Spain each collected about 6 percent over four-year periods. The revenue loss arising from the sale of those assets would also have to be considered to assess the longer-term impact on public finances. However, receipts and savings from the sales and management of nonfinancial assets have been rather small so far.

Looking forward, is selling additional government assets an option? Public financial assets are still quite large in advanced economies (more than 40 percentage points of GDP on average, half of that in the form of shares and equities). However, relying on privatization for debt reduction purposes needs careful planning and realism. Most equity holdings are in the hands of sub-national governments that may lack the incentive to sell assets, for example, due to relatively low levels of debt. The majority of public nonfinancial assets (such as land and buildings) is also owned by regional and local governments and may be difficult to monetize. Moreover, in the current economic climate, asset liquidation may not yield the same revenue as in the past. In addition, only a very small share of nonfinancial assets is considered by the authorities to be "salable" (see IMF, 2013, for a discussion on privatization).

\section{Inflation}

In principle, higher inflation could help reduce public debt. Inflation can affect the primary balance, for example if income brackets are not indexed under a progressive income tax. Governments can also capture real resources by base money creation, but the scope for raising seigniorage is limited by the small size of base money. The largest impact would be from eroding the real value of debt. Under the assumptions of a constant debt maturity structure, no 
impact of inflation on economic growth, and a one-for-one adjustment of nominal interest rates on newly issued debt to inflation (full Fisher effect), as well as on the interest rate response to higher inflation, simulations for G7 countries suggest this: a hypothetical increase in inflation from WEO baseline levels to 6 percent for five years would reduce the average net debt ratio by less than 10 percentage points by the end of the period, for most countries. ${ }^{29}$ The effect drops rapidly after five years, because an increasingly large share of securities will have been issued at higher interest rates. This is consistent with the empirical finding that inflation has not been a significant contributor to past debt reversals.

However, higher inflation would come with significant challenges and risks. As a practical matter, it might be difficult to lift inflation to a meaningful level in the current economic environment, as evidenced by Japan's experience in the last decades. More importantly, reliance on inflation to erode debt could lead to fiscal dominance, with inflation rates drifting even higher as confidence in the future value of money is lost. As a result, inflation expectations could become unanchored, thus undermining the credibility of the monetary frameworks built over the past three decades — often at significant economic cost (IMF, 2013) - to control inflation. Unanchored inflation expectation could reduce the demand for debt of longer tenor, further eroding any upside from higher inflation. This could ultimately reduce economic growth.

\section{E. Structural Reform to Lift Longer-Term Growth}

Structural reforms can lift growth and help reduce debt ratios in the longer term. Barkbu, Rahman, and Valdés (2012) survey the large empirical literature and conclude that there is substantial evidence that structural reforms can lift growth. Their simulations using the IMF's Global Monetary and Fiscal (GIMF) model show that a combination of large-scale labor, product market, and pension reforms that halve the distance of all euro area countries to bestpractice benchmarks can increase GDP by $4 \frac{1}{2} 2$ percent over a five-year horizon. The beneficial growth effects of structural reforms tend to accumulate slowly. Meanwhile, a lack of short-term demand support - be it monetary or fiscal - can have long-run effects in the opposite direction, for example through hysteresis in the labor market. To be successful, structural reforms will also have to be granular, targeting particular weaknesses. In the European example, this would include, among other things, tackling labor market duality and weak competitiveness in the South and obstacles to higher labor participation and a more vibrant services sector in the North.

\section{Conclusions}

Many advanced economies face significant challenges in reducing their public debt levels. While public debt is approaching secular highs, the continued weak medium-term growth outlook complicates the task of putting debt on a clearly declining path.

Successful past debt reversals in advanced economies often started under adverse circumstances. Output growth and fiscal policy were the main drivers behind 26 past successful episodes of public debt reductions. While some past successful episodes started under

\footnotetext{
${ }^{29}$ This section is based on Akitoby, Komatsuzaki, and Binder (forthcoming).
} 
challenging initial conditions, strong external demand and an accommodative interest rate environment supported output growth as fiscal consolidation efforts continued.

The current and expected growth environments, however, might make successful debt reversal even harder to achieve. Monetary policy is operating at or close to the lower bound, and the medium-term growth outlook is very weak. At the same time, there is little to be gained from higher rates of inflation (which would come with risks) and privatization efforts need careful planning and realism to be successful. This suggests that the burden of lowering debt levels will fall more squarely on fiscal consolidation.

Consequently, debt reductions will require both a sustained commitment to fiscal consolidation and careful design. While fiscal consolidation is needed to keep public finances sustainable, it also takes away demand and further lowers growth in the short term because of fiscal multiplier effects. Indeed, the debt ratio may actually increase initially. Up-front consolidations, while sometimes unavoidable, can lead to greater output losses than gradual efforts do, but they can also reduce risk premiums more quickly, especially if debt levels are high initially and the overall magnitude of adjustment needed is relatively large. Whether front- or back-loaded consolidations lead to more lasting success also depends on political factors, like the ability to sustain a commitment to consolidation. In any case, positive credibility effects are likely to provide only partial offsets to short-run pain.

What should policymakers do? For countries with good financial market access, the answer is to consolidate gradually but with a credible medium-term strategy, buttressed by strong budget institutions. This will minimize the adverse impact on growth, particularly if multipliers vary over time. Where fiscal accounts are weaker and sovereign rates are higher, the pace of consolidation has to be more ambitious. In all cases, it makes good sense to plan the adjustment path in structural terms to avoid the procyclical tightening that can come with a focus on headline deficits. This can be achieved, for example, by focusing on a set of pre-agreed fiscal measures that take into account the need to protect the most vulnerable and safeguard programs with strong positive growth effects (e.g., high-return infrastructure projects or key active labor market policies). Other growth-enhancing measures, such as selected structural reforms (e.g., labor markets), are important to improve growth potential in the medium term and to help reduce the debt-to-GDP ratio in a durable way. 


\section{REFERENCES}

Abbas, S. M. Ali, O. Basdevant, S. Eble, G. Everaert, J. Gottschalk, F. Hasanov, J. Park, C. Sancak, R. Velloso, and M. Villafuerte, 2010, "Strategies for Fiscal Consolidation in the Post-Crisis World", Fiscal Affairs Department Paper No. 10/04, International Monetary Fund.

Akitoby, B., T. Komatsuzaki, and A. Binder, forthcoming, "Inflation and Public Debt Reduction in the G7 Economies," IMF Working Paper (Washington: International Monetary Fund).

Alesina, A., and S. Ardagna, 2010, "Large Changes in Fiscal Policy: Taxes versus Spending," Tax Policy and the Economy [ed. by Jeffrey Brown], Vol. 24, pp. 35-68, NBER published series, University of Chicago Press.

Alesina, A., and R. Perotti, 1995, "Fiscal Expansions and Adjustments in OECD countries," Economic Policy, Vol. 21, pp. 205-40.

Barkbu, B., J. Rahman, and R. Valdés, 2012, "Fostering Growth in Europe Now," IMF Staff Discussion Note No. 12/07 (Washington: International Monetary Fund).

Batini, N., G. Callegari, and G. Melina, 2012, "Successful Austerity in the United States, Europe and Japan,” IMF Working Paper No. 12/90 (Washington: International Monetary Fund).

Baum, A., M. Poplawski-Ribeiro, and A. Weber, 2012, "Fiscal Multipliers and the State of the Economy," IMF Working Paper No. 12/286 (Washington: International Monetary Fund).

Bi, R., H. Qu, and J. Roaf, 2013, “Assessing the Impact and Phasing of Multi-year Fiscal Adjustment: A General Framework," IMF Working Paper No. 13/182 Washington: International Monetary Fund).

Blanchard, O., and D. Leigh, 2013, "Growth Forecast Errors and Fiscal Multipliers," IMF Working Paper No. 13/01 (Washington: International Monetary Fund).

Boussard, J., F. de Castro, and M. Salto, 2012, "Fiscal Multipliers and Public Debt Dynamics in Consolidations,” Economic Paper No. 460 (Brussels: European Commission).

Corsetti, G., K. Kuester, A. Meier, and G. Mueller, 2012, “Sovereign Risk, Fiscal Policy, and Macroeconomic Stability,” IMF Working Paper No. 12/33 (Washington: International Monetary Fund).

Cottarelli, C., 2013, "From Here to Eternity: The Outlook for Fiscal Adjustment in Advanced Economies," presentation delivered at the Peterson Institute for International Economies (May 20, 2013), available at http://www.imf.org/external/np/speeches/2013/052013.htm 
Cottarelli, C., and L. Jaramillo, 2012, "Walking Hand in Hand: Fiscal Policy and Growth in Advanced Economies," IMF Working Paper No. 12/137 (Washington: International Monetary Fund).

De Long, B., and L. Summers, 2012, “Fiscal Policy in a Depressed Economy,” Brookings Papers on Economic Activity (Spring 2012).

Devries, P., J. Guajardo, D. Leigh, and A. Pescatori, 2011, “A New Action-based Dataset of Fiscal Consolidation," IMF Working Paper No. 11/128 (Washington: International Monetary Fund).

Escolano, J, 2010, “A Practical Guide to Public Debt Dynamics, Fiscal Sustainability, and Cyclical Adjustment of Budgetary Aggregates." Technical Notes and Manuals No. 10/02 (Washington: International Monetary Fund).

Eyraud, L., and A. Weber, 2013, "The Challenge of Debt Reduction During Fiscal Consolidation," IMF Working Paper No. 13/67 (Washington: International Monetary Fund).

Giavazzi, G., and M. Pagano, 1996. "Non-Keynesian Effects of Fiscal Policy Changes: International Evidence and the Swedish Experience," NBER Working Papers 5332, National Bureau of Economic Research, Inc.

International Monetary Fund, 2011, Fiscal Monitor, September 2011 (Washington). , 2012, World Economic Outlook, October 2012: Coping With High Debt and Sluggish Growth (Washington). ,2013, Fiscal Monitor, April 2013 (Washington). ,2013, Reassessing the Role and Modalities of Fiscal Policy in Advanced Economies (Washington).

Mauro, P., R. Romeu, A. Binder, and A. Zaman, 2013, “A Modern History of Fiscal Prudence and Profligacy," IMF Working Paper 13/05 (Washington: International Monetary Fund).

Mineshima, A., M. Poplawski-Ribeiro, and A. Weber, 2013, "Fiscal Multipliers," in Post-Crisis Fiscal Policy, C. Cottarelli, P. Gerson, and A. Senhadji (eds.) (forthcoming; MIT Press, Cambridge, MA).

Mojon, B., and G. Peersman, 2001, “A VAR Description of the Effects of Monetary Policy in the Individual Countries of the Euro Area," ECB Working Paper No. 92 (Frankfurt: European Central Bank). 
Spilimbergo, A., S. Symansky, and M. Schindler, 2009, "Fiscal multipliers," IMF Staff Position Note No. SPN/09/11 (Washington: International Monetary Fund).

Woodford, M., 2011, "Simple Analytics of the Government Expenditure Multiplier," American Economic Journal: Macroeconomics, Vol. 3, No. 1, pp. 1-35.

Zeng, L., 2013, "Determinants of the Primary Balance: Evidence from a Panel of Countries" (forthcoming; Washington: International Monetary Fund). 


\section{Annex 1. Changes in the Debt-to-GDP Ratio}

Annex Table I.a. Changes in the Debt-to-GDP Ratio. Pink = debt increase; green = debt decrease; red border $=$ consolidation $(\triangle S P B>5)$.

\begin{tabular}{|c|c|c|c|c|c|c|c|c|c|c|c|c|c|c|c|c|c|c|c|c|c|c|c|c|c|c|c|c|c|c|c|c|c|}
\hline Country & 980 & 1981 & 1982 & 1983 & 1984 & 1985 & 19861 & 1987 & 1988 & 1989 & 1990 & 1991 & 1992 & 1993 & 1994 & 1995 & $1996 \quad$ & 1997 & 19981 & 19992 & 2000 & 20012 & 2002 & 20032 & 20042 & 2005 & 20062 & 20072 & 20082 & 2009 & 20102 & 2011 & 2012 \\
\hline Australia & -1.5 & -2.4 & -1.6 & 1.5 & 1.5 & 1.6 & 1.4 & -1.3 & 2.8 & -2.0 & -1.2 & 1.3 & 4.2 & 3.2 & 1.1 & -0.6 & -1.8 & -3.3 & -2.1 & -1.2 & -3.1 & -2.4 & -2.1 & -1.8 & -1.3 & -1.1 & -0.8 & -0.3 & 2.1 & 5.1 & 3.7 & 3.7 & 2.9 \\
\hline Austria & 1.7 & 2.1 & 2.8 & 5.1 & -1.6 & 3.0 & 2.9 & 6.3 & 4.3 & 0.0 & -2.7 & 0.2 & 0.0 & 4.5 & 3.3 & 4.2[ & -0.1 & -4.0 & 0.4 & 2.4 & -0.7 & 0.8 & -0.7 & -0.9 & -0.4 & -0.6 & -2.5 & -2.1 & 3.6 & 5.4 & 2.6 & 0.5 & 1.4 \\
\hline Belgium & & & & 10.6 & 4.3 & $\begin{array}{l}4.7 \\
\end{array}$ & 5.2 & 4.5 & 0.5 & & & 1.4 & 1.6 & 5.6 & -2.0 & -1.9 & -2.7 & $\begin{array}{r}-4.8 \\
\end{array}$ & -5.3 & -3.8 & -5.8 & -1.3 & -3.1 & -5.0 & -4.3 & -2.1 & -4.0 & -3.9 & 5.3 & 6.5 & -0.2 & 2.3 & 1.8 \\
\hline anada & 0.4 & 1.3 & 5.7 & 5.7 & 3.3 & 5.2 & 4.1 & 0.5 & -0.4 & 1.2 & 2.9 & 7.1 & 7.9 & 6.1 & 1.6 & 3.6 & 0.1 & -5.4 & -1.2 & -3.8 & -9.2 & 0.5 & -2.1 & -4.0 & -4.0 & -1.0 & -1.4 & -3.7 & 4.8 & 12.0 & 1.8 & 0.4 & 0.2 \\
\hline Cyprus & 5.1 & 2.0 & -0.4 & 3.9 & 0.2 & 0.8 & 1.6 & 4.0 & 0.8 & -4.1 & 2.7 & 3.2[ & 1.5 & 2.5 & -4.1 & & & 4.8 & 5.4 & 0.7 & -3.8 & 1.6 & 4.0 & 4.6[ & 1.2 & -1.5 & -4.7 & -5.9 & -9.9 & 9.6 & 2.9 & 10.2 & 15.0 \\
\hline Czech Republic & & & & & & & & & & & & & & & -1.7 & -2.0 & -2.1 & 0.6 & 1.9 & 1.4 & 2.1 & 6.3 & 3.4 & 1.6 & 0.4 & -0.5 & -1.4 & -0.3 & 0.8 & 5.6 & 3.3 & 3.0 & 2.6 \\
\hline Denmark & 7.7 & 9.4 & 11.4 & 6.2 & 9.4 & 4.8 & -2.2 & -5.6 & -3.4 & -0.6 & 1.1 & 1.1 & 5.0 & 3.2 & -0.9[ & 2.6 & 0.5 & & & -5.3 & -6.7 & -2.0 & -0.1 & -1.6 & -3.0 & -8.2 & -4.3 & -7.0 & 7.8 & -1.3 & 2.3 & 1.2 & 6.0 \\
\hline Estonia & & & & & & & & & & & & & & & & & -1.6 & -1.2 & -0.7 & 0.5 & -0.9 & -0.3 & 0.9 & -0.1 & -0.6 & -0.5 & -0.2 & -0.7 & 0.8 & 2.6 & -0.5 & -0.6 & 2.5 \\
\hline inland & & & 2.3 & 1.5 & -0.2 & 0.7 & 0.6 & 1.2 & -1.1 & -2.2 & -0.4 & 8.1 & 17.5 & 14.9[ & 2.3 & $\begin{array}{l}-1.0 \\
\end{array}$ & 0.2 & $\begin{array}{l}-2.9 \\
\end{array}$ & -5.2 & -2.0 & $\begin{array}{r}-1.9 \\
\end{array}$ & \begin{tabular}{|l}
$\mid-1.3$ \\
\end{tabular} & -1.0 & 3.0 & -0.1 & -2.7 & -2.1 & -4.5 & -1.2 & 9.6 & 5.1 & 0.5 & 4.2 \\
\hline France & & 1.2 & 3.3 & 1.3 & 2.4 & 1.6 & 0.5 & 2.3 & -0.1 & 0.7 & 1.2 & 0.7 & 3.8 & 6.3 & 3.2 & 6.2 & 2.6 & 1.4 & 0.1 & -0.7 & -1.4 & -0.5 & 2.1 & 4.2 & 1.9 & 1.6 & -2.6 & 0.1 & 4.0 & 11.0 & 3.1 & 3.7 & 4.3 \\
\hline ermany & 2.0 & 3.6 & 2.9 & 1.6 & 0.7 & 0.6 & -0.1 & 1.1 & 0.4 & -1.4 & 1.6 & -2.7[ & 2.5 & 3.7 & 2.2 & 7.6 & 2.9 & 1.3 & 0.7 & 0.8 & $\begin{array}{l}-1.1 \\
\end{array}$ & -1.0 & 1.6 & 3.7 & 1.8 & 2.3 & -0.6 & -2.6 & 1.6 & 7.8 & 7.7 & -1.8 & 1.4 \\
\hline Greece & 0.0 & 4.2 & 2.6 & 4.3 & 6.5 & 6.6 & 0.5 & 5.3 & 4.7 & 2.8 & $\begin{array}{l}13.4 \\
\end{array}$ & 1.5 & 5.3 & 20.4 & -2.0 & $\begin{array}{l}0.7 \\
\end{array}$ & 2.4 & -2.9 & -2.2 & 5.9 & 0.9 & 0.3 & -2.1 & -4.2 & 1.4 & 2.3 & 6.1 & 0.1 & 5.2 & 16.3 & 15.6 & 20.9 & -6.9 \\
\hline hina,P.R.: & & & & & & & & & & & & & & & & & & & & & & & 2.0 & 2.1 & 1.6 & 0.8 & -0.4 & -1.1 & -0.3 & 3.5 & -0.7 & -1.2 & 0.4 \\
\hline Iceland & & & 6.8 & 1.7 & 1.7 & -0.5 & -2.3 & -2.6 & 3.3 & 4.8 & 0.2 & 2.2 & 7.9 & 6.9 & 2.5[ & 3.3 & -2.6 & -3.2 & -5.2 & -4.5 & -2.4 & 4.8[ & -3.8 & -1.2 & -6.4 & -9.0 & 4.7 & -1.0 & 41.2 & 17.8 & 4.7 & 6.4 & -0.1 \\
\hline reland & 1.1 & 3.7 & 4.0 & 7.3 & 4.0 & 1.1 & 10.1 & 0.9 & -2.3 & $\begin{array}{l}-7.4 \\
\end{array}$ & 15.8 & 1.4 & -3.0 & 2.6 & -5.4 & -6.5 & -8.6 & -9.2 & -10.7 & -5.1 & -10.7 & -2.3 & -3.4 & -1.2 & -1.3 & -2.3 & -2.5 & 0.2 & 19.3 & 20.5 & 27.3 & 14.3 & 11.2 \\
\hline Israel & -1.2[ & & & 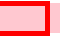 & 23.5 & -85.0 & -36.5 & -19.2 & 2.1 & 2.1 & -9.2 & -14.6 & -4.0 & -1.3 & -8.1 & -8.0 & -2.1 & -0.7 & 1.5 & -6.1 & -10.4 & 4.5 & 7.7 & 2.7 & -1.6 & -3.9 & -9.0 & -6.6 & -1.2 & 2.4 & -3.4 & -1.9 & 0.5 \\
\hline Italy & -2.2 & 2.4 & 4.7 & 6.3 & 5.5 & 6.0[ & 4.2 & 4.0 & 1.7 & 2.5 & 1.9 & 3.4 & 6.9 & 10.2 & 5.6 & -0.3 & -0.7 & -2.8 & -3.2 & -1.2 & -4.5 & -0.3 & -3.0 & -1.2 & -0.5 & 2.0 & 0.7 & -3.0 & 2.7 & 10.2 & 2.6 & 1.5 & 6.9 \\
\hline Japan & 5.2 & 4.4 & 3.8 & 4.6 & 1.5 & 1.0 & 4.4 & 1.2 & -1.8 & -1.8 & $\begin{array}{l}-3.1 \\
\end{array}$ & -0.6 & 3.5 & 6.9 & 6.4 & 6.8 & 5.9 & 8.9 & 12.5 & 14.6 & 8.3 & 13.5 & 10.4 & 5.6 & 11.1 & 5.8 & -0.4 & -3.0 & 8.8 & 18.4 & 5.0 & 14.6 & 8.0 \\
\hline Korea, Republic of & 2.9 & 1.9 & 2.4 & -0.8 & 0.3 & 0.7 & -2.5 & -2.4 & -3.0 & -3.1 & -2.0 & -0.6 & -0.1 & -0.2 & 0.2 & -0.6 & -0.3 & 3.9 & 4.6 & 2.2 & 0.4 & 0.7 & -0.1 & 3.1 & 3.0 & 4.0 & 2.5 & -0.5 & -0.5 & 3.7 & -0.3 & 0.7 & -0.5 \\
\hline Luxembourg & -0.8 & 0.4 & 0.1 & 0.5 & 0.3 & -1.4 & 1.6 & -1.2 & -1.6 & -1.1 & & & 0.7 & 1.2 & -0.5 & 1.9 & 0.0 & 0.0 & -0.3 & -0.7 & -0.3 & 0.1 & 0.0 & -0.1 & 0.1 & -0.3 & 0.6 & 0.0 & 7.0 & 1.1 & 4.3 & -0.9 & 3.0 \\
\hline Malta & & -1.6 & -0.8 & 2.3 & 0.5 & -1.1 & -2.4 & 3.6 & 2.5 & -0.3 & 4.6 & 2.8 & 1.9 & 4.7 & 1.4 & 3.5 & 5.0 & 8.6 & 5.2 & 3.9 & -1.3 & 7.5 & -4.8 & 6.5 & 3.7 & -1.2 & -5.4 & -2.0 & 0.0 & 5.7 & 1.2 & 2.6 & 0.9 \\
\hline Netherlands & 2.3 & 3.4 & 5.7 & 6.1 & 3.6 & 5.3 & 1.9 & 2.4 & 2.5 & 0.1 & 1.3[ & -0.2 & 0.7 & 1.1 & -3.2 & 0.8 & -2.0 & -5.9 & -2.5 & -4.6 & -7.3 & \begin{tabular}{|l|}
-3.1 \\
\end{tabular} & -0.2 & 1.5 & 0.4 & -0.6 & -4.4 & -2.1 & 13.2 & 2.3 & 2.1 & 2.3 & 6.6 \\
\hline New Zealand & 0.3 & -1.7 & 1.0 & 8.1 & 3.2 & 9.0 & -1.1 & 5.4 & -13.7 & -4.0 & 3.3 & -1.6[ & 4.5 & -1.5 & -6.0 & -6.4 & -5.9 & -7.8 & 0.6 & -1.8 & -2.6 & -1.2 & & & -2.3 & -1.9 & -2.5 & -2.1 & 2.9 & 6.0 & 6.2 & 5.7 & 0.0 \\
\hline Norway & -5.2 & & & & -0.2 & 2.1 & 10.3 & -8.3 & -6.5 & 0.0 & -4.0 & 12.1 & 6.8 & 10.3 & -9.9 & -12.9 & -4.3 & -3.9 & -1.5 & 0.3 & 3.5 & -0.8 & 7.2 & 9.4 & 2.5 & -3.1 & 11.1 & -2.1 & -2.5 & -5.4 & 0.7 & 0.0 & -15.5 \\
\hline Portugal & -4.0 & 7.9[ & 3.5 & 3.5 & 4.3 & 7.7 & 0.4 & -2.4 & -0.4 & -1.4 & 0.6 & 2.4 & -5.7 & 4.6 & 2.8 & 1.7 & -0.9 & -3.9 & -4.1 & -0.8 & -1.1 & 2.7 & 2.6 & 2.0 & 1.8 & 5.1 & 1.2 & 4.6 & 3.3 & 11.5 & 10.3 & 14.4 & 15.2 \\
\hline Singapore & -16.7 & -12.6 & 4.2 & 5.1 & 4.2 & 9.5 & 2.0 & 4.3 & -8.9 & -2.6 & -4.4 & 2.6 & 3.7 & -7.9 & -4.1 & 2.7 & 0.6 & -1.2 & 11.5 & 6.5 & -4.8 & 12.2 & 1.8 & 4.7 & -3.3 & -2.2 & -6.7 & -1.7 & 7.6 & 12.9 & -4.4 & 4.7 & 2.7 \\
\hline Slovak Republic & & & & & & & & & & & & & & 2.4 & -2.6 & -2.2 & -0.6 & 2.5 & 1.7 & 0.0 & 1.2 & 12.4 & 5.3 & 0.7 & -0.9 & -7.3 & -3.6 & -0.9 & -1.8 & 7.7 & 5.5 & 2.2 & 8.7 \\
\hline Slovenia & & & & & & & & & & & & & & & -2.6 & -1.5 & 3.4 & 0.6 & 0.6 & 0.8 & 7.1 & -0.5 & -0.1 & -1.4 & -0.2 & -0.6 & -0.3 & -3.4 & -1.1 & 13.1 & 3.6 & 8.3 & 5.7 \\
\hline Spain & 1.8 & 5.0 & 2.9 & 5.2 & 6.7 & 5.0 & 1.2 & -0.2 & -3.5 & 1.4 & 1.5 & 0.6 & 2.3 & 10.7 & 2.5 & 4.7[ & 4.2 & -1.3 & -2.0 & -1.7 & -3.0 & -3.8 & -3.0 & -3.8 & -2.5 & -3.1 & -3.5 & -3.4 & 3.9 & 13.8 [ & 7.2 & 7.3 & 15.6 \\
\hline Sweden & 9.4[ & 8.4 & 10.2 & 4.0 & 1.3 & -0.5 & -0.7 & -7.8 & -6.4 & -5.1 & -4.1 & 8.7 & 18.3 & 4.9[ & 4.3 & -1.4 & 3.3 & -1.4 & -1.0 & -8.8 & -8.9 & \begin{tabular}{|l|}
-1.6 \\
\end{tabular} & -2.4 & & & 0.1 & -5.2 & -5.0 & -1.4 & 3.6 & -3.2 & -0.9 & 0.1 \\
\hline Switzerland & -0.7 & -3.1 & -0.7 & -2.7 & -0.3 & -0.6 & -1.4 & -1.0 & -1.4 & -2.3 & 7.1 & 1.6 & 5.2 & 4.4[ & 3.2 & 3.3 & 2.0 & 2.1 & 3.6 & -2.6 & -0.2 & \begin{tabular}{|l}
-0.4 \\
\end{tabular} & 6.8 & -0.5 & 4.2 & 0.2 & -7.8 & -6.8 & -5.1 & 1.4 & -3.8 & -1.5 & 2.5 \\
\hline United Kingdom & -2.6 & 3.8 & -1.8 & -0.8 & 1.9 & 0.2 & 0.8 & -0.7 & -2.4 & -4.4 & -4.4 & -0.4 & 1.5 & 3.9[ & 7.2 & 4.0 & 2.5 & 0.7 & -3.2 & -2.6 & -1.7 & -1.9 & -1.1 & -0.5 & 0.3 & -5.4 & 1.2 & 0.7 & 8.5 & 15.8 & 7.0 & 6.8 & 8.5 \\
\hline ited $S$ & & -0.9 & 4.8 & 3.0 & 1.6 & $\begin{array}{r}4.9 \\
\end{array}$ & 3.4 & 1.8 & 1.0 & 0.3 & 1.7 & 4.5 & 2.4 & 1.7 & -0.8 & -0.5 & -0.8 & -2.5 & -3.2 & -3.7 & -6.0 & -0.1 & 2.4 & 3.3 & 7.8 & -0.4 & -1.2 & 0.5 & 9.0 & 13.5 & 9.0 & 4.3 & 3.6 \\
\hline
\end{tabular}


Annex Table I.b. Changes in the Debt-to-GDP Ratio. Pink = debt increase; green = debt decrease; red border = consolidation (narrative).

\begin{tabular}{|c|c|c|c|c|c|c|c|c|c|c|c|c|c|c|c|c|c|c|c|c|c|c|c|c|c|c|c|c|c|c|c|c|c|}
\hline Country & 980 & 1981 & 1982 & 1983 & 1984 & 1985 & 1986 & 1987 & 1988 & 1989 & 1990 & $\begin{array}{ll}1991 \\
\end{array}$ & 1992 & 1993 & 1994 & 1995 & 1996 & 1997 & 1998 & \begin{tabular}{l|l}
19992 \\
\end{tabular} & 2000 & 2001 & 2002 & 2003 & 2004 & 2005 & 2006 & 2007 & 2008 & 2009 & 2010 & 2011 & 2012 \\
\hline Australia & -1.5 & -2.4 & -1.6 & 1.5 & 1.5[ & 1.6 & 1.4 & -1.3 & 2.8 & -2.0 & -1.2 & 1.3 & 4.2 & 3.2[ & 1.1 & -0.6 & -1.8 & -3.3 & -2.1 & -1.2 & -3.1 & -2.4 & -2.1 & -1.8 & -1.3 & -1.1 & -0.8 & -0.3 & 2.1 & 5.1 & 3.7 & 3.7 & 2.9 \\
\hline Austria & 1.7 & 2.1 & 2.8 & 5.1[ & -1.6 & 3.0 & 2.9 & 6.3 & 4.3 & 0.0 & -2.7 & 0.2 & 0.0 & 4.5 & 3.3 & 4.2[ & -0.1 & -4.0 & 0.4 & 2.4 & -0.7 & 0.8 & -0.7 & -0.9 & -0.4 & -0.6 & -2.5 & -2.1 & 3.6 & 5.4 & 2.6 & 0.5 & 1.4 \\
\hline Belgium & & & & 10.6 & 4.3 & 4.7 & 5.2[ & 4.5 & 0.5 & & 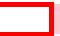 & 1.4[ & 1.6 & 5.6 & -2.0 & -1.9[ & -2.7 & -4.8 & -5.3 & -3.8 & -5.8 & -1.3 & -3.1 & -5.0 & -4.3 & -2.1 & -4.0 & -3.9 & 5.3 & 6.5 & -0.2 & 2.3 & 1.8 \\
\hline Canada & 0.4 & 1.3 & 5.7 & 5.7[ & 3.3 & 5.2 & 4.1 & 0.5 & -0.4 & 1.2 & 2.9 & 7.1 & 7.9 & 6.1 & 1.6 & 3.6 & 0.1 & -5.4 & -1.2 & -3.8 & -9.2 & 0.5 & -2.1 & -4.0 & -4.0 & -1.0 & -1.4 & -3.7 & 4.8 & 12.0 & 1.8 & 0.4 & 0.2 \\
\hline Cyprus & 5.1 & 2.0 & -0.4 & 3.9 & 0.2 & 0.8 & $1.6^{-}$ & 4.0 & 0.8 & -4.1 & 2.7 & 3.2 & 1.5 & 2.5 & -4.1 & & & 4.8 & 5.4 & 0.7 & -3.8 & 1.6 & 4.0 & 4.6 & 1.2 & -1.5 & -4.7 & -5.9 & -9.9 & 9.6 & 2.9 & 10.2 & 15.0 \\
\hline Czech Republic & & & & & & & & & & & & & & & -1.7 & -2.0 & -2.1 & 0.6 & 1.9 & 1.4 & 2.1 & 6.3 & 3.4 & 1.6 & 0.4 & -0.5 & -1.4 & -0.3 & 0.8 & 5.6 & 3.3 & 3.0 & 2.6 \\
\hline Denmark & 7.7 & 9.4 & 11.4[ & 6.2 & 9.4 & 4.8 & -2.2 & -5.6 & -3.4 & -0.6 & 1.1 & 1.1 & 5.0 & 3.2 & -0.9[ & 2.6 & 0.5 & & & -5.3 & -6.7 & -2.0 & -0.1 & -1.6 & -3.0 & -8.2 & -4.3 & -7.0 & 7.8 & -1.3 & 2.3 & 1.2 & 6.0 \\
\hline Estonia & & & & & & & & & & & & & & & & & -1.6 & -1.2 & -0.7 & 0.5 & -0.9 & -0.3 & 0.9 & -0.1 & -0.6 & -0.5 & -0.2 & -0.7 & 0.8 & 2.6 & -0.5 & -0.6 & 2.5 \\
\hline Finland & & & 2.3 & 1.5 & -0.2 & 0.7 & 0.6 & 1.2 & -1.1 & -2.2 & -0.4 & 8.1[ & 17.5 & 14.9 & 2.3 & -1.0 & 0.2 & -2.9 & -5.2 & -2.0 & -1.9 & -1.3 & -1.0 & 3.0 & -0.1 & -2.7 & -2.1 & -4.5 & -1.2 & 9.6 & 5.1 & 0.5 & 4.2 \\
\hline France & & 1.2 & 3.3 & 1.3 & 2.4 & 1.6 & 0.5[ & 2.3 & -0.1 & 0.7 & 1.2[ & 0.7 & 3.8 & 6.3 & 3.2 & 6.2 & 2.6 & 1.4 & 0.1 & -0.7 & -1.4 & -0.5 & 2.1 & 4.2 & 1.9 & 1.6 & -2.6 & 0.1 & 4.0 & 11.0 & 3.1 & 3.7 & 4.3 \\
\hline Germany & 2.0 & 3.6[ & 2.9 & 1.6 & 0.7 & 0.6 & -0.1 & 1.1 & 0.4 & -1.4 & 1.6[ & -2.7 & 2.5 & 3.7 & 2.2 & 7.6 & 2.9 & 1.3 & 0.7 & 0.8 & -1.1 & -1.0 & 1.6[ & 3.7 & 1.8 & 2.3 & -0.6 & -2.6 & 1.6 & 7.8 & 7.7 & -1.8 & 1.4 \\
\hline Greece & 0.0 & 4.2 & 2.6 & 4.3 & 6.5 & 6.6 & 0.5 & 5.3 & 4.7 & 2.8 & 13.4 & 1.5 & 5.3 & 20.4 & -2.0 & 0.7 & 2.4 & -2.9 & -2.2 & 5.9 & 0.9 & 0.3 & -2.1 & -4.2 & 1.4 & 2.3 & 6.1 & 0.1 & 5.2 & 16.3 & 15.6 & 20.9 & -6.9 \\
\hline China,P.R.: & & & & & & & & & & & & & & & & & & & & & & & 2.0 & 2.1 & 1.6 & 0.8 & -0.4 & -1.1 & -0.3 & 3.5 & -0.7 & -1.2 & 0.4 \\
\hline Iceland & & & 6.8 & 1.7 & 1.7 & -0.5 & -2.3 & -2.6 & 3.3 & 4.8 & 0.2 & 2.2 & 7.9 & 6.9 & 2.5 & 3.3 & -2.6 & -3.2 & -5.2 & -4.5 & -2.4 & 4.8 & -3.8 & -1.2 & -6.4 & -9.0 & 4.7 & -1.0 & 41.2 & 17.8 & 4.7 & 6.4 & -0.1 \\
\hline Ireland & 1.1 & 3.7 & 4.0 & 7.3 & 4.0 & 1.1 & 10.1 & 0.9 & -2.3 & -7.4 & 15.8 & 1.4 & -3.0 & 2.6 & -5.4 & -6.5 & -8.6 & -9.2 & -10.7 & -5.1 & -10.7 & -2.3 & -3.4 & -1.2 & -1.3 & -2.3 & -2.5 & 0.2 & 19.3 & 20.5 & 27.3 & 14.3 & 11.2 \\
\hline Israel & -1.2 & & & & 23.5 & -85.0 & -36.5 & -19.2 & 2.1 & 2.1 & -9.2 & -14.6 & -4.0 & -1.3 & -8.1 & -8.0 & -2.1 & -0.7 & 1.5 & -6.1 & -10.4 & 4.5 & 7.7 & 2.7 & -1.6 & -3.9 & -9.0 & -6.6 & -1.2 & 2.4 & -3.4 & -1.9 & 0.5 \\
\hline Italy & -2.2 & 2.4 & 4.7 & 6.3 & 5.5 & 6.0 & 4.2 & 4.0 & 1.7 & 2.5 & 1.9[ & 3.4 & 6.9 & 10.2 & 5.6 & -0.3 & -0.7 & -2.8 & -3.2 & -1.2 & -4.5 & -0.3 & -3.0 & -1.2 & -0.5 & 2.0 & 0.7 & -3.0 & 2.7 & 10.2 & 2.6 & 1.5 & 6.9 \\
\hline Japan & 5.2 & 4.4 & 3.8 & 4.6 & 1.5 & 1.0 & 4.4 & 1.2 & -1.8 & -1.8 & -3.1 & -0.6 & 3.5 & 6.9 & 6.4 & 6.8 & 5.9 & 8.9 & 12.5 & 14.6 & 8.3 & 13.5 & 10.4 & 5.6 & 11.1 & 5.8 & -0.4 & -3.0 & 8.8 & 18.4 & 5.0 & 14.6 & 8.0 \\
\hline Korea, Republic & 2.9 & 1.9 & 2.4 & -0.8 & 0.3 & 0.7 & -2.5 & -2.4 & -3.0 & -3.1 & -2.0 & -0.6 & -0.1 & -0.2 & 0.2 & -0.6 & -0.3 & 3.9 & 4.6 & 2.2 & 0.4 & 0.7 & -0.1 & 3.1 & 3.0 & 4.0 & 2.5 & -0.5 & -0.5 & 3.7 & -0.3 & 0.7 & -0.5 \\
\hline uxembourg & -0.8 & 0.4 & 0.1 & 0.5 & 0.3 & -1.4 & 1.6 & -1.2 & -1.6 & -1.1 & & & 0.7 & 1.2 & -0.5 & 1.9 & 0.0 & 0.0 & -0.3 & -0.7 & -0.3 & 0.1 & 0.0 & -0.1 & 0.1 & -0.3 & 0.6 & 0.0 & 7.0 & 1.1 & 4.3 & -0.9 & 3.0 \\
\hline Malta & & -1.6 & -0.8 & 2.3 & 0.5 & -1.1 & -2.4 & 3.6 & 2.5 & -0.3 & 4.6 & 2.8 & 1.9 & 4.7 & 1.4 & 3.5 & 5.0 & 8.6 & 5.2 & 3.9 & -1.3 & 7.5 & -4.8 & 6.5 & 3.7 & -1.2 & -5.4 & -2.0 & 0.0 & 5.7 & 1.2 & 2.6 & 0.9 \\
\hline Netherlands & 2.3[ & 3.4 & 5.7 & 6.1 & 3.6 & 5.3 & 1.9 & 2.4 & 2.5 & 0.1 & 1.3[ & -0.2 & 0.7 & 1.1 & -3.2 & 0.8 & -2.0 & -5.9 & -2.5 & -4.6 & -7.3 & -3.1 & -0.2 & 1.5[ & 0.4 & -0.6 & -4.4 & -2.1 & 13.2 & 2.3 & 2.1 & 2.3 & 6.6 \\
\hline New Zealand & 0.3 & -1.7 & 1.0 & 8.1 & 3.2 & 9.0 & -1.1 & 5.4 & -13.7 & -4.0 & 3.3 & -1.6 & 4.5 & -1.5 & -6.0 & -6.4 & -5.9 & -7.8 & 0.6 & -1.8 & -2.6 & -1.2 & & & -2.3 & -1.9 & -2.5 & -2.1 & 2.9 & 6.0 & 6.2 & 5.7 & 0.0 \\
\hline Norway & -5.2 & & & & -0.2 & 2.1 & 10.3 & -8.3 & -6.5 & 0.0 & -4.0 & 12.1 & 6.8 & 10.3 & -9.9 & -12.9 & -4.3 & -3.9 & -1.5 & 0.3 & 3.5 & -0.8 & 7.2 & 9.4 & 2.5 & -3.1 & 11.1 & -2.1 & -2.5 & -5.4 & 0.7 & 0.0 & -15.5 \\
\hline Portugal & -4.0 & 7.9 & 3.5[ & 3.5 & 4.3 & 7.7 & 0.4 & -2.4 & -0.4 & -1.4 & 0.6 & 2.4 & -5.7 & 4.6 & 2.8 & 1.7 & -0.9 & -3.9 & -4.1 & -0.8 & -1.1 & 2.7 & 2.6 & 2.0 & 1.8[ & 5.1 & 1.2 & 4.6 & 3.3 & 11.5 & 10.3 & 14.4 & 15.2 \\
\hline Singapore & -16.7 & -12.6 & 4.2 & 5.1 & 4.2 & 9.5 & 2.0 & 4.3 & -8.9 & -2.6 & -4.4 & 2.6 & 3.7 & -7.9 & -4.1 & 2.7 & 0.6 & -1.2 & 11.5 & 6.5 & -4.8 & 12.2 & 1.8 & 4.7 & -3.3 & -2.2 & -6.7 & -1.7 & 7.6 & 12.9 & -4.4 & 4.7 & 2.7 \\
\hline Slovak Republic & & & & & & & & & & & & & & 2.4 & -2.6 & -2.2 & -0.6 & 2.5 & 1.7 & 0.0 & 1.2 & 12.4 & 5.3 & 0.7 & -0.9 & -7.3 & -3.6 & -0.9 & -1.8 & 7.7 & 5.5 & 2.2 & 8.7 \\
\hline Slovenia & & & & & & & & & & & & & & & -2.6 & -1.5 & 3.4 & 0.6 & 0.6 & 0.8 & 7.1 & -0.5 & -0.1 & -1.4 & -0.2 & -0.6 & -0.3 & -3.4 & -1.1 & 13.1 & 3.6 & 8.3 & 5.7 \\
\hline Spain & 1.8 & 5.0 & 2.9[ & 5.2 & 6.7 & 5.0 & 1.2 & -0.2 & -3.5 L & 1.4 & 1.5 & 0.6[ & 2.3 & 10.7 & 2.5 & 4.7 & 4.2 & -1.3 & -2.0 & -1.7 & -3.0 & -3.8 & -3.0 & -3.8 & -2.5 & -3.1 & -3.5 & -3.4 & 3.9 & 13.8 & 7.2 & 7.3 & 15.6 \\
\hline Sweden & 9.4 & 8.4 & 10.2 & 4.0[ & 1.3 & -0.5 & -0.7 & -7.8 & -6.4 & -5.1 & -4.1 & 8.7 & 18.3[ & 4.9 & 4.3 & -1.4 & 3.3 & -1.4 & -1.0 & -8.8 & -8.9 & -1.6 & -2.4 & & & 0.1 & -5.2 & -5.0 & -1.4 & 3.6 & -3.2 & -0.9 & 0.1 \\
\hline Switzerland & -0.7 & -3.1 & -0.7 & -2.7 & -0.3 & -0.6 & -1.4 & -1.0 & -1.4 & -2.3 & 7.1 & 1.6 & 5.2 & 4.4 & 3.2 & 3.3 & 2.0 & 2.1 & 3.6 & -2.6 & -0.2 & -0.4 & 6.8 & -0.5 & 4.2 & 0.2 & -7.8 & -6.8 & -5.1 & 1.4 & -3.8 & -1.5 & 2.5 \\
\hline United Kingdom & -2.6 & 3.8 & -1.8 & -0.8 & 1.9 & 0.2 & 0.8 & -0.7 & -2.4 & -4.4 & -4.4 & -0.4 & 1.5 & 3.9[ & 7.2 & 4.0 & 2.5 & 0.7 & -3.2 & -2.6 & -1.7 & -1.9 & -1.1 & -0.5 & 0.3 & -5.4 & 1.2 & 0.7 & 8.5 & 15.8 & 7.0 & 6.8 & 8.5 \\
\hline ited States & 0.0 & -0.9 & 4.8 & 3.0 & 1.6[ & 4.9 & 3.4 & 1.8 & 1.0 & 0.3 & 1.7[ & 4.5 & 2.4 & 1.7 & -0.8 & -0.5 & -0.8 & -2.5 & $\begin{array}{r}-3.2 \\
\end{array}$ & -3.7 & -6.0 & -0.1 & 2.4 & 3.3 & 7.8 & -0.4 & -1.2 & 0.5 & 9.0 & 13.5 & 9.0 & 4.3 & 3.6 \\
\hline
\end{tabular}


Annex II. Country Samples Used in the Analysis

\begin{tabular}{|c|c|c|c|c|c|c|}
\hline & $\begin{array}{l}\text { Euro } \\
\text { Area }\end{array}$ & $\begin{array}{c}\text { Other } \\
\text { Advanced }\end{array}$ & $\begin{array}{c}\text { Full } \\
\text { Sample } \\
\text { (Section II) }\end{array}$ & $\begin{array}{c}\text { Main } \\
\text { Episodes }\end{array}$ & $\begin{array}{c}\text { Long } \\
\text { Episodes } \\
\text { (Section III) }\end{array}$ & $\begin{array}{c}\text { Large } \\
\text { Countries }\end{array}$ \\
\hline Australia & & * & * & & & \\
\hline Austria & * & & * & * & * & \\
\hline Belgium & * & & * & * & * & * \\
\hline Canada & & * & * & * & * & * \\
\hline Cyprus & * & & & * & & \\
\hline Czech Republic & & * & * & & & \\
\hline Denmark & & * & * & * & * & \\
\hline Estonia & * & & * & & & \\
\hline Finland & * & & * & * & * & \\
\hline France & * & & * & & & \\
\hline Germany & * & & * & & & \\
\hline Greece & * & & * & * & & \\
\hline Hong Kong SAR & & * & * & & & \\
\hline Iceland & & * & * & * & * & \\
\hline Ireland & * & & * & * & * & \\
\hline Israel & & * & & * & * & \\
\hline Italy & * & & * & * & * & * \\
\hline Japan & & * & * & * & & * \\
\hline Korea & & * & * & & & \\
\hline Netherlands & * & & * & * & * & * \\
\hline New Zealand & & * & * & * & * & \\
\hline Norway & & * & & & & \\
\hline Portugal & * & & * & * & & \\
\hline Slovak Republic & * & & * & & & \\
\hline Slovenia & * & & * & & & \\
\hline Spain & * & & * & * & * & * \\
\hline Sweden & & * & * & * & * & * \\
\hline Switzerland & & * & * & * & * & * \\
\hline United Kingdom & & * & * & * & & * \\
\hline United States & & * & * & * & * & * \\
\hline
\end{tabular}

Source: Fund staff. 
Annex III. Major Debt Reduction Episodes in Advanced Economies Since 1980

\begin{tabular}{|c|c|c|c|c|c|c|c|c|c|}
\hline & \multirow[b]{2}{*}{$\begin{array}{c}\text { Episode } \\
\text { length } \\
\text { (yrs) }\end{array}$} & \multirow[b]{2}{*}{$\begin{array}{l}\text { Debt reduction } \\
(\text { from } \rightarrow \text { to), } \\
\text { percent of GDP }\end{array}$} & \multirow{2}{*}{$\begin{array}{l}\text { Debt } \\
\text { reduction } \\
\text { per year } \\
\text { ("speed") }\end{array}$} & \multicolumn{6}{|c|}{ Average level observed over episode (percentage points) } \\
\hline & & & & $\begin{array}{c}\text { Structural primary } \\
\text { balance } \\
\text { (ppt of GDP) }\end{array}$ & $\begin{array}{l}\text { Interest- } \\
\text { growth } \\
\text { differential }\end{array}$ & $\begin{array}{c}\text { Real } \\
\text { effective } \\
\text { interest rate }\end{array}$ & $\begin{array}{l}\text { Real GDP } \\
\text { growth } \\
\text { rate }\end{array}$ & $\begin{array}{c}\text { Nominal } \\
\text { effective } \\
\text { interest rate }\end{array}$ & $\begin{array}{c}\text { CPI } \\
\text { inflation }\end{array}$ \\
\hline GRC 2000-03 & 3 & $6(104 \rightarrow 98)$ & 2.0 & 0.9 & -2.6 & 2.0 & 4.5 & 5.6 & 3.5 \\
\hline JPN 1984-91 & 7 & $6(74 \rightarrow 67)$ & 0.9 & 4.2 & -2.4 & 2.9 & 5.4 & 5.3 & 2.3 \\
\hline AUT 2001-07 & 6 & $7(67 \rightarrow 60)$ & 1.1 & 0.9 & 0.3 & 2.8 & 2.5 & 4.7 & 1.8 \\
\hline NLD 2004-07 & 3 & $7(52 \rightarrow 45)$ & 2.4 & 2.0 & -0.6 & 3.0 & 3.1 & 4.6 & 1.6 \\
\hline PRT 1995-00 & 5 & $11(59 \rightarrow 48)$ & 2.1 & 0.1 & -0.2 & 4.0 & 4.2 & 6.5 & 2.4 \\
\hline DNK 1985-89 & 4 & $12(68 \rightarrow 57)$ & 3.0 & 8.5 & 6.8 & 8.7 & 1.4 & 12.5 & 3.5 \\
\hline GBR 1986-91 & 5 & $12(50 \rightarrow 38)$ & 2.5 & 1.7 & 0.2 & 2.9 & 2.7 & 8.7 & 5.7 \\
\hline GBR 1996-01 & 5 & $14(51 \rightarrow 38)$ & 2.7 & 3.6 & 1.6 & 5.1 & 3.5 & 6.6 & 1.3 \\
\hline NZL 1986-88 & 2 & $14(72 \rightarrow 58)$ & 6.9 & 1.1 & -6.3 & -5.3 & 1.0 & 5.2 & 11.1 \\
\hline FIN 1994-02 & 8 & $16(58 \rightarrow 41)$ & 2.0 & 4.4 & 0.8 & 4.8 & 4.0 & 6.6 & 1.7 \\
\hline USA 1993-00 & 7 & $17(72 \rightarrow 55)$ & 2.5 & 2.0 & -2.0 & 2.1 & 4.0 & 4.6 & 2.5 \\
\hline ITA 1994-03 & 9 & $(122 \rightarrow 104)$ & 2.0 & 4.3 & 2.3 & 3.9 & 1.6 & 6.8 & 2.8 \\
\hline ISR 2004-08 & 4 & $21(98 \rightarrow 77)$ & 5.1 & 1.5 & -1.0 & 3.0 & 5.1 & 5.2 & 2.1 \\
\hline SWE $1985-90$ & 5 & $21(61 \rightarrow 40)$ & 4.2 & 3.2 & 0.7 & 3.3 & 2.6 & 9.7 & 6.2 \\
\hline CYP 2004-08 & 4 & $23(72 \rightarrow 49)$ & 5.7 & 4.4 & -3.2 & 2.3 & 4.2 & 5.0 & 2.7 \\
\hline CHE 2005-11 & 6 & $25(72 \rightarrow 47)$ & 4.2 & 1.8 & -1.2 & 1.0 & 2.1 & 1.7 & 0.8 \\
\hline NLD 1993-01 & 8 & $28(78 \rightarrow 51)$ & 3.5 & 2.7 & 0.8 & 4.4 & 3.5 & 6.8 & 2.4 \\
\hline ESP 1996-07 & 11 & $31(67 \rightarrow 36)$ & 2.8 & 2.1 & -1.7 & 2.1 & 3.8 & 5.1 & 2.9 \\
\hline ISL 1995-05 & 10 & $34(59 \rightarrow 25)$ & 3.4 & 3.2 & -1.2 & 3.4 & 4.6 & 7.0 & 3.5 \\
\hline SWE 1996-08 & 12 & $34(73 \rightarrow 39)$ & 2.9 & 3.3 & 0.5 & 3.6 & 3.0 & 5.0 & 1.3 \\
\hline CAN 1996-07 & 11 & $35(102 \rightarrow 67)$ & 3.2 & 6.7 & 1.8 & 5.1 & 3.3 & 7.3 & 2.1 \\
\hline NZL 1992-07 & 15 & $45(62 \rightarrow 17)$ & 3.0 & 4.2 & 1.2 & 4.8 & 3.6 & 7.1 & 2.1 \\
\hline BEL 1993-07 & 14 & $50(134 \rightarrow 84)$ & 3.6 & 4.9 & 1.4 & 3.8 & 2.4 & 5.7 & 1.8 \\
\hline DNK 1993-07 & 14 & $53(80 \rightarrow 28)$ & 3.8 & 4.2 & 2.0 & 4.5 & 2.4 & 6.6 & 2.0 \\
\hline ISR 1989-00 & 11 & $53(147 \rightarrow 84)$ & 4.8 & 0.7 & -11.3 & -4.0 & 5.9 & 5.9 & 10.3 \\
\hline IRE 1987-07 & 20 & $84(109 \rightarrow 25)$ & 4.2 & 3.6 & -3.1 & 2.7 & 5.7 & 5.6 & 2.9 \\
\hline Simple avg. & 8 & $26(79 \rightarrow 53)$ & 3.2 & 3.1 & -0.6 & 3.0 & 3.5 & 6.2 & 3.2 \\
\hline Median & 7 & $25(72 \rightarrow 49)$ & 3.0 & 3.0 & 0.0 & 3.0 & 4.0 & 6.0 & 2.0 \\
\hline
\end{tabular}

Source: Fund staff calculations.

Annex IV. Relationship Between Primary Balance, Debt-to-GDP Ratio, and Growth 


\section{Density of Debt and Structural Primary Balance Changes Conditional on Macroeconomic Variables}

Densities of debt changes are similar whether conditioning on the overall primary balance...

... or its structural component.
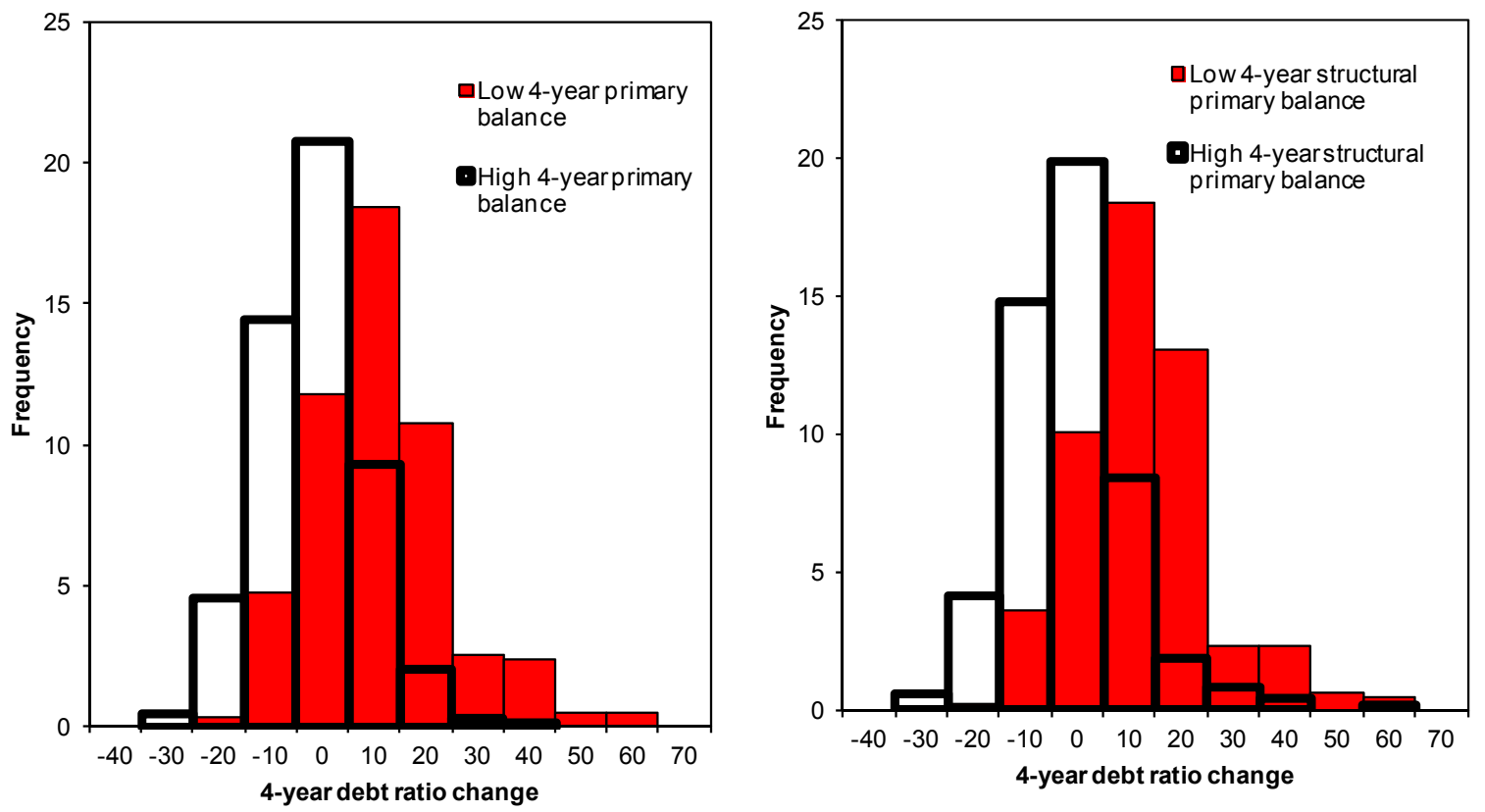

Higher structural primary balances are associated with higher potential growth...

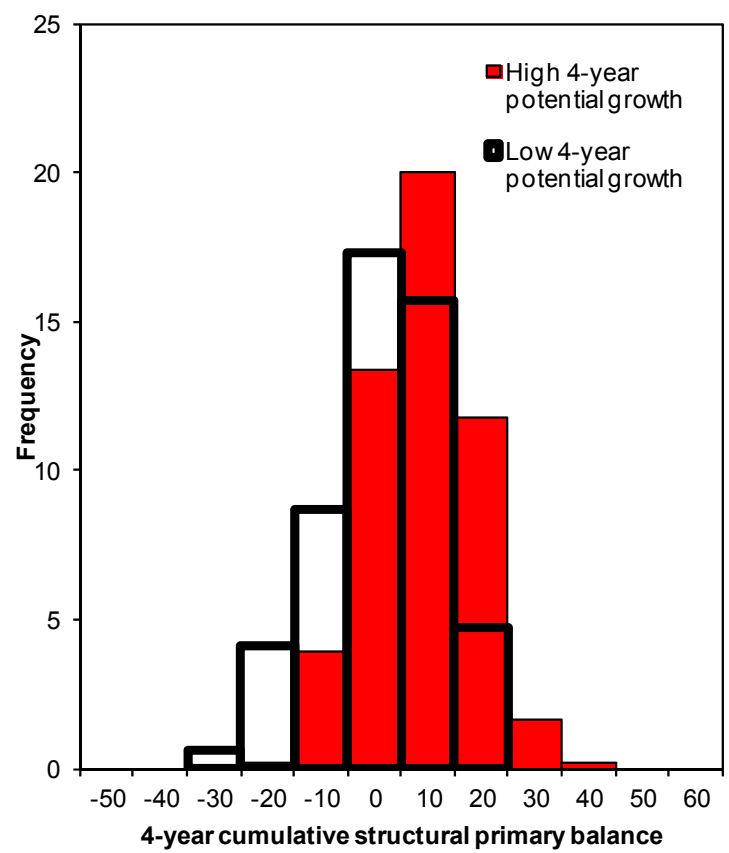

...but not higher cyclical growth

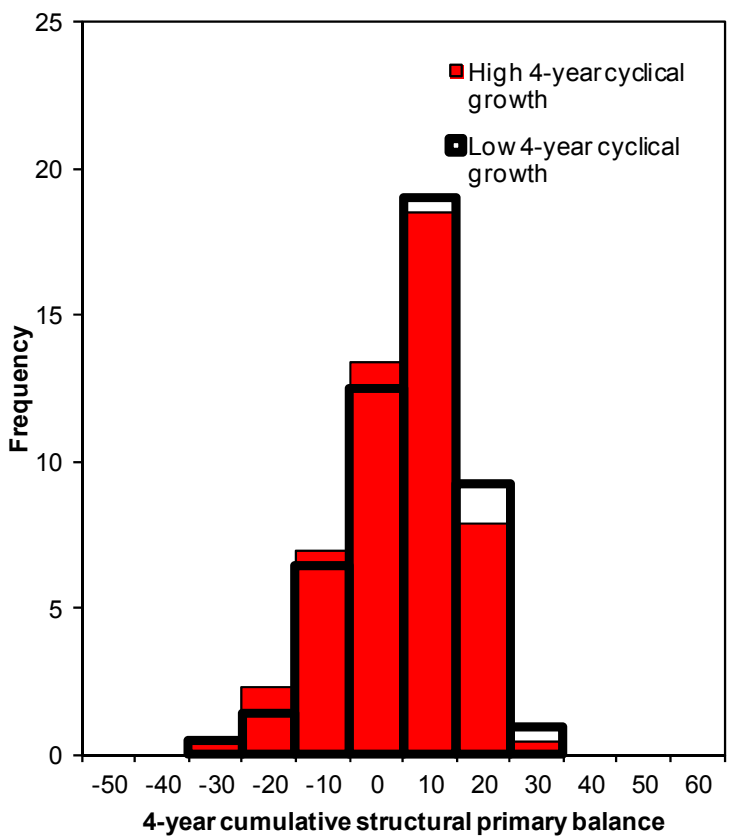

Sources: IMF World Economic Outlook and Fund staff calculations.

Note: Each panel shows two densities of debt ratio changes or cumulative structural primary balances where primary balances, or potential and cyclical growth rates are below or above their country median. 


\section{Annex V. Illustrative Framework for Debt Dynamics Equation}

\section{A. Baseline Framework}

The framework is designed to show the interactions inherent in the dynamic debt equation between fiscal consolidation efforts, growth, inflation, and interest rates. The framework describes the development of the debt-ratio over time, driven by the assumed behavior of variables such as output trend and risk premiums, as well parameters such as fiscal policy multipliers.

\section{Output}

In the framework, output is assumed to evolve in line with the potential growth rate of GDP, with deviations from this underlying rate caused by only by fiscal shocks and risk premiums effects. Baseline growth follows:

$$
y_{t}=y_{t-1}\left(1+g+\theta\left(r_{t}-r^{*}\right)\right)\left(1+\pi_{t}\right)
$$

Where $y$ is the level of output $g$ is the underlying, or potential, growth rate of GDP, $\left(r-r^{*}\right)$ captures deviations of the real interest rate from the underlying, or equilibrium, rate, and $\pi$ is the GDP deflator. $\theta$ is the elasticity of output to $100 \mathrm{bps}$ change in the interest rate. ${ }^{30}$

\section{Interest rates}

Interest rates have two real components: an underlying, or equilibrium, rate and a risk premium. In the baseline, the Fisher effect is assumed to hold, but frictions can be introduced in scenarios. Financial conditions in the economy are assumed to be correlated with sovereign borrowing costs:

$$
i_{t}=\left(1+\left(r^{*}+r p_{t}\right)\right)(1+\pi)-1
$$

Where $i$ is the nominal interest rate, $r^{*}$ is the underlying, or equilibrium, interest rate, and $r p$ is the risk premium. The risk premium in the baseline has the following non-linear form:

$$
r p_{t}=\frac{1}{\left(d_{\max }-d_{t-1}\right)^{\alpha}}
$$

Where $d_{\max }$ is an exogenously set maximum parameter for the debt-to-GDP ratio, $d$ is the debt-to-GDP ratio, and $\alpha$ is a chosen parameter.

\section{Inflation}

Inflation is driven by an underlying trend rate, although the framework also allows for inflationary shocks (one-off changes to the rate of inflation):

\footnotetext{
${ }^{30}$ This specification for the interest elasticity of output builds on Batini et al. (2012).
} 


$$
\pi_{t}=\pi^{*}+\varepsilon_{t}
$$

\section{Fiscal policy}

Fiscal variables evolve in line with the following equations:

$$
r e v_{t}=r r \cdot y_{t}
$$

Where $r e v_{t}$ is nominal government revenue and $r r$ is an exogenously chosen revenue ratio or effective tax rate. In other words, the elasticity of revenue to output is assumed to be one.

Primary expenditures follow:

$$
\operatorname{pexp}_{t}=p s r \cdot y_{t}^{b}-\Delta s p b_{t}
$$

Where pexp is government primary spending $y^{b}$ is the level of output that would have prevailed at $t$ in the baseline (i.e. before the adjustment), psr is an exogenously chosen primary spending ratio in the baseline scenario, and $\Delta s p b$ is the change in structural primary balance and reflects the fiscal effort in that period.

\section{Fiscal adjustment}

\section{B. Policy Scenarios}

All fiscal adjustment, whether front-loaded or gradual, is measured against the medium-term fiscal plans that prevailed before the adjustment started. Adjustment is defined in levels, with the final improvement in the primary balance falling short of $\Delta s p b$, at least in the short-run, to the endogenous impact of consolidation on output (the so-called multiplier effect).

\section{Output}

Consequently, under fiscal adjustment, the growth equation becomes:

$$
y_{t}=y_{t-1}\left(1+g+\theta\left(r_{t}-r^{*}\right)-f_{t}\right)\left(1+\pi_{t}\right)
$$

Where $f$ represents the drag on growth from fiscal effort. This term is the sum of the products of all current and earlier fiscal consolidation efforts (as a percent of GDP) and their respective marginal multipliers in that period $(m){ }^{31}$ The persistence of the multiplier, that is the time for output to return to potential, is an exogenous parameter. See the table below for an example:

\footnotetext{
${ }^{31}$ Fiscal consolidation as a percent of GDP in $\mathrm{t}$ is converted to a "growth rate" from $\mathrm{t}-1$ by multiplying by $(1+\mathrm{g})$.
} 


\begin{tabular}{|c|c|c|c|c|}
\hline & $\mathbf{t}=\mathbf{1}$ & $t=2$ & $\mathbf{t}=\mathbf{3}$ & $t=4$ \\
\hline$(\Delta \mathrm{spb} / \mathrm{y}) 1$ & $\mathrm{ml} \cdot(\Delta \mathrm{spb} / \mathrm{y}) 1$ & $\mathrm{~m} 2 \cdot(\Delta \mathrm{spb} / \mathrm{y}) 1$ & $\mathrm{~m} 3 \cdot(\Delta \mathrm{spb} / \mathrm{y}) 1$ & $\mathrm{~m} 4 \cdot(\Delta \mathrm{spb} / \mathrm{y}) 1$ \\
\hline$(\Delta \mathrm{spb} / \mathrm{y}) 2$ & & $\mathrm{~m} 1 \cdot(\Delta \mathrm{spb} / \mathrm{y}) 2$ & $\mathrm{~m} 2 \cdot(\Delta \mathrm{spb} / \mathrm{y}) 2$ & $\mathrm{~m} 3 \cdot(\Delta \mathrm{spb} / \mathrm{y}) 2$ \\
\hline$(\Delta \mathrm{spb} / \mathrm{y}) 3$ & & & $\mathrm{~m} 1 \cdot(\Delta \mathrm{spb} / \mathrm{y}) 3$ & $\mathrm{~m} 2 \cdot(\Delta \mathrm{spb} / \mathrm{y}) 3$ \\
\hline$(\Delta \mathrm{spb} / \mathrm{y}) 4$ & & & & $\mathrm{~m} 1 \cdot(\Delta \mathrm{spb} / \mathrm{y}) 4$ \\
\hline$\sum$ & $\mathbf{f}_{1}$ & $\mathbf{f}_{2}$ & $\mathbf{f}_{3}$ & $\mathrm{f}_{4}$ \\
\hline
\end{tabular}

\section{Interest rates}

Fiscal effort already impacts interest rates by changing debt levels (equation 3 ). In this case, fiscal effort that increases the debt-to-GDP ratio (the so-called multiplier effect) in the shortrun would increase interest rates. However, it is possible that markets react favorably to announced fiscal consolidation plans. To allow for this possibility, an additional term is added to risk premium equation in the policy scenarios. It is assumed that all adjustment is implemented as announced.

Therefore, equation 3 becomes:

$$
r p_{t}=\frac{1}{\left(d_{\max }-d_{t-1}\right)^{\alpha}}-\beta\left(\frac{\Delta s p b_{-} c u m_{t}}{y_{t}}\right)
$$

Where $\Delta s p b_{-} c u m$ is the cumulative change in the structural primary balance since the start of any fiscal adjustment process. The risk premium reflects the only deviation of interest rates from their equilibrium levels in the model and hence the $r p_{t}$ term effectively replaces the $\left(r-r^{*}\right)$ term in the equations 1 and 7 .

In the policy scenarios, nominal interest rates may not fully adjust to changes in inflation due to frictions. The extent of pass-though is determined by the following equation:

$$
\Delta i_{t}=\varepsilon_{t}\left(1-e^{-\emptyset}\right)
$$

where $\emptyset$ is a parameter set greater than zero.

\section{Debt dynamics}

The government is assumed to issue a bond $(B)$ of a fixed maturity $(q)$ in each period. Each bond covers both the redemption of the earlier bond issued in $\mathrm{t}-\mathrm{q}$ and the overall deficit in $\mathrm{t}$. Debt is measured at the end of the period.

$$
D_{t}=\sum_{j=t-q+1}^{t} B_{j}
$$

This gives an expression for the government interest bill: 


$$
\text { int }_{t}=\sum_{j=t-q}^{t-1} B_{j} \quad i_{j}
$$

Where $i$ is the marginal interest rate on new debt as defined in equation 2 . The effective interest rate $i_{t}^{e}$ can be obtained by dividing by the debt-stock in the last period:

$$
i_{t}^{e}=\sum_{j=t-q}^{t-1} i_{j}\left(B_{j} / D_{t-1}\right)
$$

That is, the effective interest rate is the weighted average of past marginal (nominal) rates. From the equations 2 and 11, innovations to the risk premium and inflation feed through into the effective interest rate gradually as a function of the maturity/redemption structure and the overall balance. As a consequence, debt evolves in line with the standard debt dynamics equation:

$$
\Delta d_{t}=\frac{i^{e}-\gamma}{(1+\gamma)} d_{t-1}-p b_{t}
$$

where $p b$ is the primary balance and $\gamma$ is the nominal growth rate that follows from equation 7 .

\section{Calibration}

The baseline dynamics were calibrated broadly in line with features of a typical advanced economy in the euro area:

- Output growth. Potential output growth is low at 1.2 percent (broadly in line with staff forecasts for euro area averages over 2013-18). As highlighted in the main text, higher output growth rates lead to better baseline debt-dynamics.

- $\quad$ Fiscal variables. The revenue ratio is set at just below 40 percent of GDP and the primary spending ratio just above, giving a primary deficit of 1 percent of GDP. This primary balance is broadly in line with advanced economy averages over 2013-18 (IMF, 2013). Average euro area primary balances over this horizon are higher at almost 1 percent of GDP, but these already incorporate fiscal adjustment that is modeled separately in this framework.

- Interest rates. The underlying interest real rate is set at 2 percent in order to generate an interest bill of around 3.5 percent of GDP at t (broadly in line with 2012 average euro area interest bill). Lower/higher underlying rates, lead to better/worse debt-dynamics in the baseline, but do not have a significant impact on the difference between the baseline and policy scenarios.

- Risk premiums (fiscal effort). The "consolidation" term $(\beta)$ in equation 8 is calibrated to fall within the range of interest rate responses to fiscal effort found in the literature (see Table 4, Boussard and others, 2012). It is set to 15 basis points for each 1 percent of GDP fiscal adjustment for the calculations behind Figures 6 and 7, but increased to 30 basis points for the calculations behind Figure 8 to highlight the potential impact that credibility effects could have on debt-dynamics. 
- $\quad$ Risk premiums (debt-level). The non-linear specification in equation 3 is calibrated to give a plausible range of interest rate responses to increases in the debt-ratio based on recent empirical evidence (see Table 8, IMF, 2013). D_max is set to 170 percent of GDP and $\alpha$ is set to 1.5. Changing the slope of this risk premiums curve can quickly affect baseline dynamics, with a very steep curve leading to debt crisis in the absence of some fiscal policy response. However, a steeper curve also increases the positive impact of credibility effects in the policy response scenario.

- $\quad$ Starting debt-to-GDP ratio. This is set to 90 percent of GDP, broadly in line with the 2012 euro area average. The starting debt-to-GDP ratio is increased to 130 percent of GDP in the calculations behind Figure 8 (closer to the average for euro area countries under stress) to show the impact that credibility effects could have on debt-dynamics.

- Fiscal multipliers. The fiscal multiplier is set to 1 in most calculations, in line with the estimates for fiscal multipliers in the current economic environment found in Eyraud and Weber (2013). ${ }^{32}$ Higher/lower assumptions lead to a greater/lesser short-run impact on growth from fiscal adjustment, but don't affect longer-term dynamics as output is assumed to return to potential. The persistence of the multiplier was set at 4 years to broadly match the persistence seen in the impulse response functions of VAR estimates. For the calculations behind Figure 7, a "recessionary" multiplier of 1.5 was chosen, in line with estimates in Batini and others (2012).

- Interest elasticity of output. The term $\theta$ in equations 1 and 7 was set to -0.2 , within the range of estimates found in the literature (see for example Mojon and Peersman, 2001). ${ }^{33}$ It follows from this specification that risk premiums affect debt-dynamics through two channels: the interest bill of the sovereign (direct effect) and output growth by also affecting private-sector borrowing costs (indirect effect).

- Inflation: Underlying inflation is set to 2 percent. In simulations (not shown in the paper) various a variety of inflation surprises were used. A durable effect on debt-dynamics only occurred if there as an imperfect Fisher Effect (i.e. $\varnothing$ in equation 9 is very small).

The framework is transparent and reasonably robust to variations in key parameters. The dynamic debt equation is the workhorse model of a large number of studies and its characteristics are well understood in the literature (see Escolano, 2010). Allowing, for example, the fiscal multiplier to vary within a plausible range of 0.2 to 1.5 - a range capturing the vast majority of recent research on advanced economies (Mineshima and others, 2013) does not significantly alter the main findings discussed.

\footnotetext{
${ }^{32}$ The estimates of fiscal multiplier incorporate the effects of monetary policy, but not the effects of risk premiums on interest rates as these are assumed to be separate.

${ }^{33}$ In Figure 8 , varying $\theta$ by $+0.1 /-0.1$ changes the final debt-to-GDP ratio with credibility effects by $+3 /-3$ percentage points.
} 